\title{
DYNAMIC SPECKLE INTERFEROMETRY OF MICROSCOPIC AND MACROSCOPIC PROCESSES IN DEFORMABLE MEDIA
}

\author{
A. P. Vladimirov \\ Institute of Engineering Science, Ural Branch of the Russian Academy of Sciences, 34 Komsomolskaya st., \\ Ekaterinburg, Russian Federation \\ *Corresponding author. E-mail: vap52@,bk.ru; address for correspondence: ul. Komsomolskaya 34, 620049, \\ Ekaterinburg, Russian Federation. Tel.:+7 343 3753598; fax: +7 3433745330.
}

The paper briefly considers the theory of the dynamic variant of optical speckle interferometry and its application to study in real time macroscopic and microscopic processes in deformable media. In the theoretical part, it is shown that it is convenient to study the macroscopic translational displacement, rotation and deformation of bodies by the movement of the whole picture of speckles and the shift of interference fringes of the two speckle fields, while the microscopic phenomena are conveniently studied by the change of the structure of speckle images. The paper presents some applications of original techniques developed by the author to determine rotations and strains of bodies under elastic and plastic deformations, to detect ultrasonic waves and to study the characteristics of crack initiation in high-cycle fatigue. Practical application of the developed techniques for testing macro- and microprocesses in living cells is shown.

Keywords: speckles, speckle dynamics, speckle interferometry, displacement, deformation, rotation, damage, high-cycle fatigue, crack, residual life, living cells, metabolism.

DOI: $10.17804 / 2410-9908.2015 .6 .027-057$

\section{References}

1. Anisimov I.V., Kozel S.M., Lokshin G.R. Space-time statistical properties of coherent radiation scattered by a moving diffuse reflector. Optics and Spectroscopy, 1969, vol. 27, iss. 3, pp. 483-491.

2. Yoshimura T. Statistical properties of dynamic speckles. Journal of the Optical Society of America A, 1986, vol. 3, no. 2, pp. 1032-1054.

3. Veselov L.M., Popov I.A. Information properties of a time-varying speckle pattern. Optics and Spectroscopy, 1993, vol. 74, iss. 6, pp.685-686.

4. Ruth B., Haina D., Waidelich W. Vibration analysis by speckle counting. Optica Acta: International Journal of Optics, 1983, vol. 30, iss. 6, pp. 841-848. DOI: 10.1080/713821265.

5. Aleksandrov E.B., Bonch-Bruevich A. M. Investigation of Surface Strains by the Hologram Technique. Soviet Physics-Technical Papers, 1967, vol. 12, pp. 258-265.

6. Leendertz J.A. Interferometric displacement measurement on scattering surfaces utilizing speckle effect. Journal of Physics E: Scientific Instruments, vol. 3, no. 3, pp. 214-218. DOI: $10.1088 / 0022-3735 / 3 / 3 / 312$.

7. Vladimirov A.P., Mikushin V.I. Interferometric determination of vector components of relative displacements: theory and experiment. In: Valery V. Tuchin, Vladimir P. Ryabukho, Dmitry A. Zimnyakov, eds. Saratov Fall Meeting '98: Light Scattering Technologies for Mechanics, Biomedicine, and Material Science, Proceedings of SPIE. Saratov, Russia, 1999, vol. 3726, pp. 38-43. DOI: 10.1117/12.341416.

8. Yamaguchi I. Speckle displacement and decorrelation in the diffraction and image fields for small object deformation. Optica Acta: International Journal of Optics, 1981, vol. 27, iss. 10, pp. 1359-1376. DOI: 10.1080/713820454. 
9. Vladimirov A.P. Dinamicheskaya spekl-interferometriya deformiruemykh obyektov [Dynamic Speckle Interferometry of Objects under Deformation]. A Doctoral Thesis, Ekaterinburg, 2002, 393 p. (In Russian).

10. Vladimirov A.P. Dinamicheskaya spekl-interferometriya deformiruyemykh tel. [Dynamic Speckle Interferometry of Bodies under Deformation]. Ekaterinburg, UrO RAN Publ., 2004, 241 p. (In Russian).

11. Vladimirov A.P., Udartsev E.V. The second-order speckle mechano-optical effect: theory and experiment. In: Dmitry A. Zimnyakov, Vladimir L. Derbov, Leonid A. Melnikov, Lev M. Babkov, eds. Saratov Fall Meeting 2002: Laser Physics and Photonics, Spectroscopy, and Molecular Modeling III; Coherent Optics of Ordered and Random Media III, Proceedings of SPIE. Saratov, Russian Federation, 2003, vol. 5067, pp. 99-106. DOI: 10.1117/12.518491.

12. Vladimirov A.P., Mikushin V.I., Lisin A.L. Optical method of determining the components of the relative displacement vector. Technical Physics Letters, 1999, vol. 25, iss. 24, pp. $1008-1010$.

13. Vladimirov A.P., Popov D.O. Rigid Rotations of a plate and the related speckle displacements in the image plane. Technical Physics Letters, 2003, vol. 29, iss. 10, pp. 855-857.

14. Popov D.O., Vladimirov A.P. Methods for the determination of strains by speckle displacements. In: Proceedings of the $4^{\text {th }}$ Scientific-Technical Conference "Resurs i diagnostika materialov i konstruktsiy", Ekaterinburg, 2009, pp. 51. (In Russian).

15. Wolf E. Intensity fluctuations in stationary optical fields. Philosophical Magazine, 1957, vol. 2, iss. 5, pp. 351-354. DOI: 10.1080/14786435708243824.

16. Vladimirov A.P., Druzhinin A.V., Malygin A.S., Mikitas K.N. Theory and calibration of speckle dynamics of phase object. In: Valery V. Tuchin; Elina A. Genina; Igor V. Meglinski, eds. Saratov Fall Meeting 2011: Optical Technologies in Biophysics and Medicine XIII, Proceedings of SPIE. Saratov, Russian Federation, 2012, vol. 8337, pp. 83370C: 1-15. DOI: 10.1117/12.924800.

17. Vladimirov A.P. Dynamic speckle interferometry of the microscopic processes. In: Ángel F. Doval, Cristina Trillo, J. Carlos Lopez-Vazquez, eds. Speckle 2012: V International Conference on Speckle Metrology, Proceedings of SPIE. Vigo, Spain, 2012, vol. 8413, pp. 8413 841305: 1-6. DOI: $10.1117 / 12.2184567$.

18. Pugachev V.S. Teoriya sluchainykh funktsiy [Theory of Random Functions]. M, Fizmatgiz Publ., 1962, 884 p. (In Russian).

19. Vladimirov A.P. Time-average dynamic speckle interferometry. In: Enrico Primo Tomasini, ed. 11th International Conference on Vibration Measurements by Laser and Noncontact TechniquesAivela 2014: Advances and Applications, Proceedings of AIP Conference Ancona, Italy, 2014, vol. 1600, pp. 237-242. DOI: 10.1063/1.4879588.

20. Vladimirov A.P. Dynamic speckle interferometry of microscopic processes in thin biological objects. Radiophysics and Quantum Electronics, 2015, vol. 57, iss. 8, pp. 564-576. DOI: $10.1007 / \mathrm{s} 11141-015-9540-2$.

21. Yamaguchi I., Takemori T., Kobayachi K. Stabilized and accelerated speckle strain gauge. In: Ryszard J. Pryputniewicz, ed. Laser Interferometry: Quantitative Analysis of Interferograms: Third in a Series, Proceedings of SPIE. San Diego, 1989, vol. 1162, pp. 187-200. DOI: $10.1117 / 12.962746$.

22. Vladimirov A.P., Eremin P.S. Relative displacement determination of surfaces of two objects by means of speckle-field dynamic interference in the image plane. In: Dmitry A. Zimnyakov; Vladimir L. Derbov; Leonid A. Melnikov; Lev M. Babkov, eds. Laser Physics and Photonics, Spectroscopy, and Molecular Modeling III; Coherent Optics of Ordered and Random Media III, Proceedings of SPIE. Saratov, Russian Federation, 2003, vol. 5067, pp. 91-98. DOI: 10.1117/12.518490.

23. Vladimirov A.P., Kapustin D.S. Comparative analysis of dynamic and holographic interferometry methods with reference to deformations of a membrane. Russian Journal of Nondestructive Testing, 2004, vol. 40, iss. 1, pp. 61-65. 
24. Ed. Aleshin A. P. Metody akusticheskogo kontrolya metallov [Methods for Acoustic Testing of Metals]. M., Mashinostroenie Publ., 1989, 456 p. (In Russian).

25. Bazylev P.V., Bondarenko A.N., Lugovoy V.A. A laser unit designed for measuring Rayleigh surface wave velocity. Defektoskopiya, 1990, no. 10, pp. 91-93. (In Russian).

26. Trillo C., Doval A.F., Cernadas D., Lopez O., Lopez J.C., Dorrıo B.V., Fernandez J.L., Perez-Amor M. Measurement of the complex amplitude of transient surface acoustic waves using double-pulsed TV holography and a two-stage spatial Fourier transform method. Measurement Science and Technology, 2003, vol. 14, no. 12, pp. 2127-2134. DOI: 10.1088/0957-0233/14/12/012.

27. Vladimirov A.P., Gorkunov E.S., Eremin P.S., Zadvorkin S.M. Microdistortions in the crystal lattice of steel IIIX15 as estimated via the optoacoustic method and velocimetry. Russian Journal of Nondestructive Testing, 2006, vol. 42, iss. 9, pp. 582-585. DOI: 10.1134/S1061830906090038.

28. Vladimirov A.P., Gorkunov E.S., Eremin P.S., Zadvorkin S.M., Shadrin M.V., Solov'ev K.E. A speckle-interferometric setup for contactless measurements of the velocity of Rayleigh ultrasonic waves. Instruments and Experimental Techniques, 2010, vol. 53, iss. 1, pp 118-121. DOI: $10.1134 / \mathrm{S} 0020441210010197$.

29. Vladimirov A.P., Gorkunov E.S., Goruleva L.S., Zadvorkin S.M., Shadrin M.V. A speckle-interferometric setup for determining the velocity of ultrasonic rayleigh waves on millimeter-size segments. Russian Journal of Nondestructive Testing, 2011, vol. 47, iss. 3, pp. 153-157. DOI: $10.1134 / \mathrm{S} 1061830911030107$.

30. Gilanyi A., Morishita K., Sukegawa T., Uesaka M., Miya K. Magnetic nondestructive evaluation of fatigue damage of ferromagnetic steels for nuclear fusion energy systems. Fusion Engineering and Design, 1998, vol. 42, iss. 1-4, pp. 485-491.

31. Tupikin D.A. Thermoelectric testing of fatigue phenomena. Kontrol. Diagnostika, 2003, no. 11, pp. 53-61. (In Russian).

32. Ignatovich S.R., Shmarov V.N., Yutskevich S.S. Peculiarities of the formation of the deformation relief on the surface of the D16AT alloy under fatigue. Aviatsionno-kosmicheskaya tekhnika i tekhnologiya, 2009, no. 10 (67), pp. 132-136.

33. Ermishkin V.A., Murat D.P., Podbelsky V.V. Application of the photometric analysis of structural images to the evaluation of resistance to fatigue fracture. Avtomatizatsiya i sovremennye tekhnologii, 2008, no. 2, pp 11-21.

34. Plekhov O.A., Panteleev I.A., Leontiev V.A. Особенности выделения тепла и генерации сигналов акустической эмиссии при циклическом деформировании армко-железа. Fizicheskaya mezomekhanika, 2009, vol. 12, no. 5, pp. 37-43.

35. Marom E. Holographic correlation. In: Golograficheskie nerazrushayushchie issledovaniya [Holographic Nondestructive Investigtions]. M., Mashinostroenie Publ., 1979, pp. 164-194.

36. Marom E., Muller R.K. Optical correlation for impending fatigue failure detection. International Journal of Nondestructive Testing, 1971, vol. 3, iss. 2, pp. 171-187.

37. Kozubenlo V.P., Potichenko V.A., Borodin Yu.S. Examination of fatigue of metals by the speckle-correlation. Strength of Materials, 1989, vol. 21, iss. 7, pp. 953-958. DOI: $10.1007 / \mathrm{BF} 01529623$.

38. Kamantsev I.S., Vladimirov A.P., Borodin E.M. Исследование процессов зарождения трещин при многоцикловой усталости трубной стали 09Г2С с использованием метода спеклинтерферометрии. Vestnik $T G U, 2013$, vol. 18, iss. 4, pp. 1881-1882. (In Russian).

39. Vladimirov A.P., Kamantsev I.S., Ishchenko A.V., Gorkunov E.S., Gladkovsky S.V. Изучение процесса зарождения усталостной трещины по изменению рельефа поверхности образца и ее спекловых изображений. Deformatsiya i razrushenie materialov, 2015, no. 1, pp. 21-26. (In Russian).

40. Vladimirov A.P., Kamantsev I.S., Veselova V.E., Gladkovski S.V. Using speckle images correlation for real-time inspection of fatigue crack initiation and propagation. In: Peter Lehmann, Wolfgang Osten, Amanda Albertazzi G. Jr., eds. Optical Measurements Systems for Industrial Inspection IX, Proceedings of SPIE. Munich, Germany, 2015, vol. 9525, pp. 952525: 1-6. DOI: 10.1117/12.2184703.

Vladimirov A. P. / Dynamic speckle interferometry of microscopic and macroscopic processes in deformable media 
open-aCCeSS journal

41. Eds. Rabal H.J, Braga R.A. Dynamic Laser Speckle and Applications, CRC Press, 2008.

42. Briers J.D. Laser speckle contrast imaging for measuring blood flow. Optica Applicata, 2007, vol. 37, iss. 1-2, pp 139-152.

43. Malygin A.S., Bebenina N.V., Vladimirov A.P., Mikitas K.N., Baharev A.A. A speckleinterferometric device for studying the cell biological activity. Instruments and Experimental Techniques, 2012, vol. 55, iss. 3, pp. 415-418.

44. Vladimirov A.P., Malygin A.S., Mikhailova Yu.A., Bakharev A.A., Poryvaeva A.P. Retrofit Device for Real-Time Evaluation of Metabolic Activity in Herpes Virus Infected Cell Cultures. Biomedical Engineering, 2014, vol. 48, iss. 14, pp. 178-181. DOI: $10.1007 / \mathrm{s} 10527-014-9447-9$.

45. Vladimirov A.P., Baharev A.A., Malygin A.S., Mikhailova J.A., Novoselova I.A., Yakin D.I. Application of speckle dynamics for studies of cell metabolism. In: Pietro Ferraro, Simonetta Grilli, Monika Ritsch-Marte, David Stifter, eds. Optical Methods for Inspection, Characterization, and Imaging Biomaterials II, Proceedings of SPIE. Bellingham, WA, 2015, vol. 9529, pp. 95291F: 1-10. DOI: 10.1117/12.2184605.

46. Baharev A.A., Vladimirov A.P., Malygin A.S., Mikhailova Y.A., Novoselova I.A., Yakin D.I., Druzhinin A.V Dynamic speckle-interferometer for intracellular processes analyses at high optical magnification. In: Pietro Ferraro, Simonetta Grilli, Monika Ritsch-Marte, David Stifter, eds. Optical Methods for Inspection, Characterization, and Imaging Biomaterials II, Proceedings of SPIE. Bellingham, WA, 2015, vol. 9529, pp. 95291G: 1-9. DOI: 10.1117/12.2184622.

47. Tikhomirov A.M. Impedans biologicheskikh tkanei i ego primenenie v meditsine [Impedance of biological tissues and its application in medicine]. M, RGMU Publ., 2006, 12 p. 
Подана в журнал: 17.08 .2015 г.

УДК 535.417:620.16

DOI: $10.17804 / 2410-9908.2015 .6 .027-057$

\title{
ДИНАМИЧЕСКАЯ СПЕКЛ-ИНТЕРФЕРОМЕТРИЯ МИКРОСКОПИЧЕСКИХ И МАКРОСКОПИЧЕСКИХ ПРОЦЕССОВ В ДЕФОРМИРУЕМЫХ СРЕДАХ
}

\author{
А. П. Владимиров
}

\begin{abstract}
Федеральное государственное бюджетное учреждение науки Институт машиноведения Уральского отделения Российской академии наук, ул. Комсомольская, 34, Екатеринбург, Российская Федерация

*Ответственный автор. Электронная почта: vap52@bk.ru; адрес для переписки: ул. Комсомольская, 34, 620049, Екатеринбург, Российская Федерация. Телефон: +7 (343) 375-35-98; факс: +7 (343) 374-53-30
\end{abstract}

Кратко рассмотрены теория динамического варианта оптической спеклинтерферометрии и ее применение для изучения в реальном масштабе времени макроскопических и микроскопических процессов, протекающих в деформируемых средах. В теоретической части показано, что макроскопические поступательные перемещения, повороты и деформации тел удобно изучать по перемещению всей картины спеклов, а также по смещению интерференционных полос двух спекл-полей, в то время как микроскопические явления - по изменению структуры спекловых изображений. В работе приведены примеры применения разработанных автором оригинальных методик для определения поворотов, деформаций при упругих и пластических деформациях тел, регистрации ультразвуковых волн, а также для изучения особенностей зарождения трещины при многоцикловой усталости материалов. Показано практическое применение разработанных методов для контроля макро- и микропроцессов в живых клетках.

Ключевые слова: спеклы, динамика спеклов, спекл-интерферометрия, перемещения, деформации, повороты, повреждения, многочикловая усталость, трещина, остаточный ресурс, живые клетки, метаболизм.

\section{1. Введение}

Если шероховатый объект осветить когерентным оптическим излучением, то вблизи объекта и за линзой, которая формирует изображение объекта, возникает макроскопически однородное, но в микроскопическом смысле неоднородное распределение интенсивности рассеянного излучения. В силу того, что высоты микрорельефа поверхности случайны, волны, отраженные от разных микроскопических площадок поверхности, имеют случайные амплитуды и фазы. В результате взаимной интерференции множества таких волн и возникает пятнистая или «спекловая» структура рассеянного излучения.

При нарушении по какой-либо причине поверхности объекта изменяются амплитуды и фазы отраженных волн, следовательно, изменяется и картина спеклов. Изменение амплитуд и фаз волн может быть обусловлено перемещением объекта как целого и его жестким поворотом или малыми изменениями расстояний между площадками вследствие упругих деформаций поверхности. Причиной может быть малое или сильное изменение микрорельефа поверхности из-за коррозии, разрыхления материала ионизирующим излучением, усталостью материалов и т.д. Указанные макроскопические и микроскопические процессы могут протекать одновременно.

Следует отметить, что картину спеклов можно сформировать и при изучении объектов с зеркальной поверхностью, а также прозрачных объектов, осветив их через матовое стекло. К примеру, таким объектом являются живые клетки, культивированные или осажденные на прозрачной подложке. Установлено, что при наличии свободного пространства 
клетки могут изменять свою форму, а внутриклеточные процессы случайным образом изменяют фазы прошедших сквозь клетку волн.

Таким образом, по характеру изменения картины спеклов становится возможным изучать и контролировать явления, происходящие на поверхности или вблизи поверхности отражающих тел или внутри прозрачных сред.

Если два деформируемых тела осветить когерентным излучением от одного источника света, а затем с помощью систем зеркал наложить спекловые их изображения, то в области перекрытия спеклов возникнет квазипериодическое изменение интенсивности излучения, вызванное относительным перемещением двух тел. Данное явление также можно использовать для анализа деформаций тел.

В настоящее время известно использование изменений, смещений и интерференции спекл-полей для изучения макроскопических явлений, а именно: для определения перемещений, скорости движения, поворотов и упругих деформаций тел [1-7]. Вместе с тем логика развития оптики спеклов и нужды практики ставят задачу анализа не только макроскопических, но и микроскопических процессов, протекающих на структурном уровне. Например, подобная задача возникает при изучении явлений, сопровождающих зарождение трещины при многоцикловой усталости металлических материалов, а также при анализе процессов, протекающих в мембране клеток живых систем. Актуальность таких исследований связана с разработкой методики оценки остаточного ресурса элементов конструкций, а в случае биологических объектов выбором лекарственных средств для конкретного пациента.

В данной статье под микроскопическим процессом понимается процесс, протекающий на структурном уровне. Считается, что параметры, характеризующие такой процесс, получаются усреднением на отрезке, длина которого равна характерному размеру структуры объекта. Параметры, характеризующие макроскопическое явление, определяются на базах, превышающих пространственный интервал корреляции параметров, характеризующих микроскопический процесс.

Поскольку свойства материалов на структурном уровне случайны, то амплитуды и фазы, отраженных от объекта или прошедших сквозь объект волн, случайным образом изменяются в пространстве и во времени. В общем случае решение задачи по установлению связи между параметрами, характеризующими динамику фаз волн, и динамикой спеклов, является очень непростой задачей. В последнее время наблюдается определенный прогресс в решении подобных задач. Целью данного обзора является обсуждение известных, а также новых результатов, полученных при разработке методов динамической спекл-интерферометрии и ознакомление с возможностями их практического применения. В краткой теоретической части статьи рассматриваются связи между перемещениями, поворотами и деформациями элементов среды, детерминировано изменяющими фазы отраженных или пошедших сквозь объект волн и параметрами, характеризующими динамику спеклов и интерференцию спеклполей. Анализируются также соотношения между величинами, характеризующими случайные изменения фаз волн и параметрами динамики спеклов. Обосновывается метод усреднения спеклов во времени, использование которого позволило при изучении микроскопических процессов получать хорошо воспроизводимые данные. Рассматриваются недавно полученные результаты по практическому применению метода усреднения во времени, а именно: для изучения процесса зарождения трещин при многцикловой усталости материалов без остановки циклического нагружения и для анализа активности живых клеток при наличии внешних воздействий. 


\section{2. Теория рассеяния когерентного излучения деформируемой средой}

\section{1 Геометрия свободного пространства}

\subsection{1 Динамика спеклов в свободном поле}

Динамика спеклов в свободном пространстве, вызванная деформациями освещенного участка поверхности, впервые теоретически подробно была изучена И. Ямагучи [8]. Он рассмотрел случай, когда направления освещения и наблюдения близки к нормали изучаемой плоской поверхности. Рассматривались двумерные перемещения спеклов в плоскости, расположенной на некотором расстоянии от объекта. В работе [9] были изучены закономерности динамики спеклов в более общей постановке задачи. Рассматривался малый трехмерный прозрачный объект с точечными центрами рассеяния при произвольном расположении в пространстве источника света и точки наблюдения. Исследовались трехмерные перемещения, повороты, однородные деформации объекта, и вызванные ими трехмерные смещения спеклов. Кроме того, в отличие от Ямагучи, предполагалось, что фазы волн вблизи центров рассеяния могут изменяться случайным образом. Предполагалось также, что отсутствует многократное рассеяние волн, случайные амплитуды и фазы волн, координаты, число центров рассеяния независимы, но имеется корреляция случайных фаз волн во времени. Используя эти приближения, мы получили выражение для функции взаимной корреляции интенсивности излучения в двух пространственно-временных точках $\vec{q}, t$ и $\vec{q}+\Delta \vec{q}, t_{2}$, равное произведению двух функций:

$$
B_{1,2}\left(\vec{q}, t_{1} ; \vec{q}+\Delta \vec{q}, t_{2}\right)=B_{1,2}(\vec{u}, \varepsilon, \Omega, \Delta \vec{q}) \times B_{1,2}\left(t_{1}, t_{2}\right) .
$$

Первая функция, зависящая от пространственных координат, определялась следующим выражением:

$$
B_{1,2}(\vec{u}, \varepsilon, \Omega, \Delta \vec{q})=\left|\langle N\rangle \frac{1}{V_{0}} \iiint_{V} \sqrt{I_{01}(\vec{r}) I_{02}(\vec{r}+\vec{u})} \exp \left\{-i k F_{0}(x, y, z)\right\} d x d y d z\right|^{2}
$$

где $\vec{u}$ - вектор поступательного перемещения объекта; $\varepsilon$ - тензор малых деформаций; $\Omega$ - тензор поворотов объекта; $\Delta \vec{q}$ - вектор, соединяющий две точки наблюдения; $\langle N\rangle$ - среднее по ансамблю число центров рассеяния; $V_{0}$ - объем области $V ; I_{01}(\vec{r})$ и $I_{02}(\vec{r}+\vec{u})$ - распределения освещающего излучения в моменты времени $t_{1}$ и $t_{2}$ соответственно; начало декартовой системы координат находилось в пределах области $V ; F_{0}(x, y, z)-$ кубическая форма уравнения $F_{0}(x, y, z)=0$ :

$$
\begin{gathered}
F_{0}(x, y, z)=e_{111} x^{3}+e_{222} y^{3}+e_{333} z^{3}+e_{112} x^{2} y+e_{113} x^{2} z+e_{221} y^{2} x+e_{223} y^{2} z+ \\
+e_{331} z^{2} x+e_{332} z^{2} y+e_{123} x y z+e_{11} x^{2}+e_{22} y^{2}+e_{33} z^{2}+e_{12} x y+e_{13} x z+e_{23} y z+ \\
+e_{1} x+e_{2} y+e_{3} z+e_{0} .
\end{gathered}
$$

Выражения для коэффициентов кубической формы $e_{111}, \ldots, e_{3}$, кроме несущественного члена $e_{0}$, приведены в Приложении 1 работы [9].

Коэффициенты $e_{i}, e_{i j}, e_{i j k}(i, j, k=1,2,3)$ зависят от расстояний $\rho_{S}, \rho_{q}$ от начала координат до источника излучения и до точки $\vec{q}$ соответственно, от компонент векторов $\vec{u}, \Delta \vec{q}$,

Vladimirov A. P. / Dynamic speckle interferometry of microscopic and macroscopic processes in deformable media 
тензоров $\Omega$ и $\varepsilon$, а также от компонент единичных векторов $\vec{l}_{S}$ и $\vec{l}$, направленных от начала координат к источнику излучения и $\vec{q}$, соответственно.

Автокорреляционная функции $B_{1,2}\left(t_{1}, t_{2}\right)$, зависящая только от временных координат, в точности совпадает с аналогичной функцией, полученной при изучении динамики спеклов в области изображения объекта. Поэтому свойства этой функции будут рассмотрены в разд. 2.2.2.

Вектор $\Delta \vec{q}$, соединяющий точку $\vec{q}$ и положение пика функции $B_{1,2}(\Delta \vec{q})$, является и вектором перемещения спеклов. Автору не удалось установить для общего случая аналитические соотношения между перемещениями, деформациями, поворотами области $V$ и компонентами вектора перемещения спеклов из-за сложности аналитического вычисления интеграла в (2). Вывод таких соотношений может быть предметом дальнейших исследований. Вместе с тем анализ формул (2) и (3) показал, что если углы между направлением освещения и направлениями наблюдения достаточно велики $(\geq \pi / 6)$, то в выражении (3) членами, содержащими в виде сомножителей $e_{i j}$ и $e_{i j k}$, можно пренебречь. В этом случае интеграл в (2) легко берется, а между компонентами вектора $\Delta \vec{q}$, вектора $\vec{u}$, тензоров $\varepsilon, \Omega$ появляется линейная связь. Таким образом, освещая лучом лазера участок поверхности и определяя из эксперимента в окрестности разных точек наблюдения компоненты вектора смещения спеклов $\Delta \vec{q}$, из системы линейных уравнений можно определить все девять неизвестных - компоненты вектора $\vec{u}$, тензоров $\varepsilon$ и $\Omega$. Конкретная реализация этой методики в общем виде является предметом дальнейших исследований.

В монографии [10] были представлены некоторые частные случаи, в которых динамика спеклов возникает вследствие различных типов поступательных перемещений, поворотов, деформаций или их комбинаций. Модельные эксперименты показали хорошее согласие с теорией. Теоретически было показано, что если на поверхности плоского объекта деформации $\varepsilon_{x x}$ и $\varepsilon_{y y}$ не равны нулю, то имеет место перемещение спеклов по нормали поверхности. Данный эффект был выявлен при термическом расширении образца в форме цилиндра. Описание этого опыта можно найти в работах $[10,11]$.

\subsection{2 Интерференция спекловых волн, отраженных от двух деформируемых тел}

Если два отдельных шероховатых объекта или два участка одного объекта осветить когерентным излучением от одного источника света, то в свободном пространстве возникнут два спекл-поля. Поскольку в пределах одного спекла волновой фронт в первом приближении можно рассматривать как однородный, то в области перекрытия двух спеклов возникает картина интерференции, как в опыте Юнга по интерференции двух волн. Период или ширина интерференционных полос $\Delta$ равна $\lambda /[2 \sin (\theta / 2)]$, где $\theta$ - угол между линиями, проведенными от точки наблюдения к центрам освещенных участков.

В [10] представлено решение теоретической задачи об интерференции спекл-полей, отраженных от двух деформируемых тел. В этой задаче использовалась рассмотренная в предыдущем параграфе модель деформируемого рассеивающего тела. Предполагалось, что тела перемещаются поступательно, поворачиваются и деформируются произвольным образом, а вблизи центров рассеяния фазы волн изменяются случайным образом. Было установлено, что повороты, деформации и случайные изменения фаз волн приводят к смещениям и изменению картины спеклов, а изменение периода интерференционных полос (сдвиг полос) возможен только при поступательном перемещении объектов. Для интенсивности излучения I в произвольной точке наблюдения была получена формула:

Vladimirov A. P. / Dynamic speckle interferometry of microscopic and macroscopic processes in deformable media 


$$
I=I_{1}+I_{2}+2 I_{12} \cos \left\{k\left[\Delta \rho-\vec{u}_{10}\left(\vec{l}_{s 1}+\vec{l}_{q 1}\right)+\vec{u}_{20}\left(\vec{l}_{s 2}+\vec{l}_{q 2}\right)+\varphi_{0}\right]\right\}
$$

где $I_{1}$ и $I_{2}$ - интенсивности излучения в точке при отсутствии поочередно второго и первого тела соответственно; $I_{12}$ - амплитуда периодически изменяющейся интенсивности, зависящая от перемещений, поворотов и деформаций тел, а также от случайно изменяющихся фаз волн; $k=\lambda /(2 \pi) ; \Delta \rho$ - разность величин $\rho_{S}+\rho_{q}$ для двух тел; $\vec{u}_{10}$ и $\vec{u}_{20}$-поступательные перемещения первого и второго тела соответственно; $\vec{l}_{s 1}+\vec{l}_{q 1}-$ сумма единичных векторов, направленных от центра первого объекта к источнику света и в точку наблюдения соответственно; $\vec{l}_{s 2}+\vec{l}_{q 2}-$ аналогичная сумма для второго объекта; $\varphi_{0}-$ константа, учитывающая случайный скачок фазы при переходе от одного спекла к другому.

Из формулы следует, что если в шести точках свободного пространства зафиксировать периоды интерференции, то можно определить компоненты векторов $\vec{u}_{10}$ и $\vec{u}_{20}$. В $[10,11]$ экспериментально было показано, что если направления освещения и наблюдения объектов выбраны таким образом, что сумма $-\vec{u}_{10}\left(\vec{l}_{s 1}+\vec{l}_{q 1}\right)+\vec{u}_{20}\left(\vec{l}_{s 2}+\vec{l}_{q 2}\right)$ равна нулю, то положение интерференционных полос не меняется вплоть до уменьшения $I_{1}$ или $I_{2}$ до нуля. В том случае, когда указанная сумма не равна нулю, происходит смещение интерференционных полос.

Пусть $\vec{l}_{s 1}=\vec{l}_{s 2}=\vec{l}_{s}, \quad \vec{l}_{q 1}=\vec{l}_{q 2}=\vec{l}_{q}$, что можно обеспечить на практике с помощью систем зеркал. Введем вектор относительного перемещения $\Delta \vec{u}=\vec{u}_{20}-\vec{u}_{10}$. Тогда из (4) следует, что

$$
\Delta \vec{u}\left(\vec{l}_{s}+\vec{l}_{q}\right)=\lambda \Delta N
$$

где $\Delta N=N-N_{0} ; \quad N$ и $N_{0}$ - порядки полос до и после перемещения тел на $\Delta \vec{u}$. Отметим, что выражение (5) точно совпадает с аналогичной формулой в голографической интерферометрии. Выведенная в работе [12] формула (5) была использована для определения разности перемещения двух освещенных участков упруго деформированного цилиндра и определения его деформации. Было установлено хорошее совпадение между деформациями, найденными по интерференции спекл-полей и с помощью электрического тензометра. Применение этого варианта интерференции спекл-полей для регистрации ультразвуковых колебаний рассмотрено в разд. 3.

Из формулы (4) следует, что когда мы работаем с одним объектом, то $\vec{u}_{10}=\vec{u}_{20}=\vec{u}$, $\vec{l}_{s 1}=\vec{l}_{s 2}=\vec{l}_{s}$. При выборе двух направлений наблюдения и совмещении с помощью системы зеркал спекловых волн, распространяющихся вдоль выбранных направлений, в области перекрытия двух спеклов действует формула $\vec{u}\left(\vec{l}_{q 1}-\vec{l}_{q 2}\right)=\lambda \Delta N$. Как видно, данная формула позволяет реализовать эксперимент по определению компонент вектора $\vec{u}$.

\section{2 Однолинзовая система наблюдения}

\subsection{1 Динамика спеклов в области изображения деформируемого тела}

Для плоского отражающего объекта при направлениях освещения и наблюдения, близких к нормали, на основе модели точечных рассеивателей, непрерывно занимающей некоторую область, задача о динамике спеклов в области изображении поверхности была решена 
open-access journal

И. Ямагучи [8]. В отличие от [8], в работе [9] сделано обобщение на случай трехмерного деформируемого тела, произвольного расположения источника излучения и при наличии случайных изменений фаз вблизи рассеивающих центров. Динамика спеклов рассчитывалась на основе модели трехмерной деформируемой рассеивающей среды, рассмотренной в разд. 2.1.1. Обозначения, принятые в расчетах работы [9], приведены на рис.1.

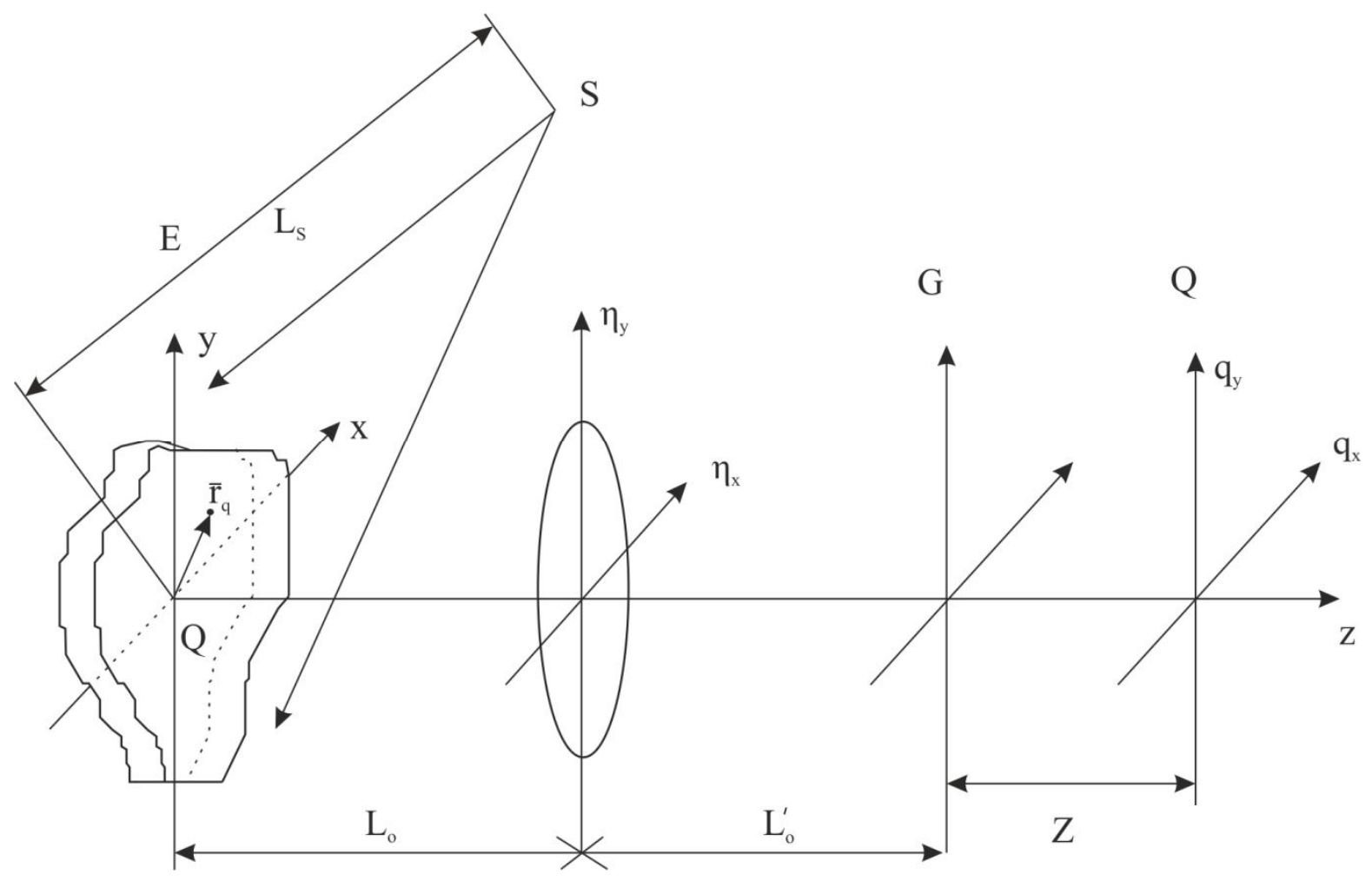

Рис. 1. Система координат и обозначения

Здесь $\mathrm{E}$ и $\mathrm{G}$ - это сопряженные плоскости; $\mathrm{Q}$ - плоскость наблюдения, которая располагается на расстоянии $Z$ от плоскости $G$. Прозрачное тонкое трехмерное тело толщиной $2 Z_{0}$ с расположенными внутри точечными рассеивающими центрами освещается источником когерентного излучения с длиной волны $\lambda$ из точки $\mathrm{S}$. Главной задачей анализа, как и ранее, являлось вычисление функции корреляции интенсивности излучения $B_{1,2}\left(t_{1}, t_{2}, \vec{q}, \vec{q}+\Delta \vec{q}\right)$. В расчете используются следующие приближения: в окрестности точки $\vec{r}_{q}$, сопряженной точке $\vec{q}$, имеется большое число центров рассеяния; повороты и деформации среды однородны; случайные изменения разности фаз пар волн вблизи центров рассеяния скоррелированы во времени. В этих приближениях выражение для функции корреляции интенсивности излучения в двух пространственно-временных точках имеет вид:

$$
\begin{gathered}
B_{1,2}\left(t_{1}, t_{2}, \vec{q}, \vec{q}+\Delta \vec{q}\right)=B_{1,2}\left(t_{1}, t_{2}\right) \mid \frac{1}{2 Z_{0}} \int_{-Z_{0}}^{Z_{0}} e^{-i k F_{0 s z} z} d z \int_{-\infty}^{\infty} \int p(\vec{\eta}) p^{*}\left(\vec{\eta}+\vec{A}_{p}\right) \\
\left.\cdot \exp \left\{+i k \frac{\vec{\eta}}{L_{0}^{\prime}+Z}[\Delta \vec{q}-\vec{A}(\vec{u}, \Omega, \varepsilon)]\right\} d^{2} \vec{\eta}\right|^{2}
\end{gathered}
$$

где $B_{1,2}\left(t_{1}, t_{2}\right)$ - временная автокорреляционная функция интенсивности излучения; $F_{0 s z}, \vec{A}_{p}$ и $\vec{A}(\vec{u}, \Omega, \varepsilon)$ - величины, зависящие от вектора поступательного перемещения $\vec{u}$ точки $\vec{r}_{q}$ и от

Vladimirov A. P. / Dynamic speckle interferometry of microscopic and macroscopic processes in deformable media 
поворотов и деформаций в ее окрестности $[9,10]$. В частности для компоненты вектора перемещения спеклов $A_{y}\left(\vec{u}_{0}, \Omega, \varepsilon\right)$ было получено следующее выражение:

$$
\begin{gathered}
A_{y}\left(\vec{u}_{0}, \Omega, \varepsilon\right)=-m u_{y 0}+\frac{Z}{L_{0}^{\prime}}\left\{\left(-m u_{y 0}-u_{y 0}\right)-L_{0}\left[\left(\varepsilon_{x y}-\Omega_{z}\right) l_{s x}+\right.\right. \\
\left.\left.+\varepsilon_{y y} l_{s y}+\left(\varepsilon_{y z}+\Omega_{x}\right)\left(l_{s z}+1\right)+\frac{1}{L_{s}} u_{x 0} l_{s x} l_{s y}+\frac{1}{L_{s}} u_{y 0}\left(l_{s y}^{2}-1\right)+\frac{1}{L_{s}} u_{z 0}\left(l_{s y} l_{s z}\right)\right]\right\} .
\end{gathered}
$$

Из формулы (6) следует, что функция достигает максимума при $\Delta \vec{q}=\vec{A}(\vec{u}, \Omega, \varepsilon)$, следовательно, вектор $\vec{A}$ является вектором перемещения спеклов. Анализ формулы (6) показал также, что если $Z=0$, т.е. динамика спеклов регистрируется в плоскости изображения объекта, то смещения спеклов вызываются только поступательными перемещениями объекта, а декорреляция спекл-поля может быть обусловлена как перемещениями, так и деформациями и поворотами. В том же случае, когда плоскость наблюдения смещена относительно плоскости изображения объекта $(Z \neq 0)$, смещения спеклов могут быть вызваны также деформациями и поворотами. Эти случаи были подробно рассмотрены при разработке методик определения поворотов [13] и деформаций [14] элементов поверхности (разд. 3).

\subsection{2 Микроскопические процессы и динамика спеклов}

Временная функция корреляции интенсивности излучения $B_{1,2}\left(t_{1}, t_{2}\right)$, учитывающая случайные изменения фаз волн, фигурирующая в формулах (1) и (6), имела следующий вид:

$$
B_{1,2}\left(t_{1}, t_{2}\right)=e^{-k_{11}-k_{22}+2 k_{12}}
$$

где $k_{11}$ и $k_{22}$ - дисперсии фаз волн в моменты времени $t_{1}$ и $t_{2}$ соответственно; $k_{12}-$ смешанный корреляционный момент фаз волн в моменты времени $t_{1}$ и $t_{2}$. Следует отметить, что при выводе выражения (8) было использовано часто применяющееся предположение, что функция корреляции интенсивности излучения равна квадрату модуля взаимной интенсивности [15]. Равенство справедливо, если в точке наблюдения реальная и мнимая части суммарной комплексной амплитуды распределены по закону Гаусса, а фаза однородно распределена в интервале от $-\pi$ до $+\pi$. В работах $[16,17]$ выражение $B_{1,2}\left(t_{1}, t_{2}\right)$ для отражающего и тонкого прозрачного объекта было получено без использования такого упрощения. В предположении, что случайной величиной является не фаза волны, а разность фаз $x$ пар волн, вместо (8) было получено

$$
B_{1,2}\left(t_{1}, t_{2}\right)=I^{2} N(N-1) \cos \left(\left\langle x_{1}\right\rangle-\left\langle x_{2}\right\rangle\right) e^{-\frac{1}{2} k_{11}-\frac{1}{2} k_{22}+k_{12}},
$$

где $I$ - интенсивность, соответствующая одному центру рассеяния; $N$ - число центров рассеяния, расположенных в области, размер которой равен линейному разрешению линзы; $\left\langle x_{1}\right\rangle$ и $\left\langle x_{2}\right\rangle$ - средние по ансамблю объектов значения $x$ в моменты времени $t_{1}$ и $t_{2}$ соответственно. Из формулы (9) следует, что если микроскопические процессы случайным образом изменяют фазы прошедших сквозь тонкий объект или отраженных волн, то по величине $\mathrm{B}_{1,2}\left(\mathrm{t}_{1}, \mathrm{t}_{2}\right)$ мож- 
но контролировать среднее значение, отклонения от среднего и время корреляции (релаксации) фаз волн.

Если процесс изменения разности фаз волн стационарен и однороден, то $\left\langle x_{1}\right\rangle=\left\langle x_{2}\right\rangle$, $k_{11}=k_{22}, k_{12}=k_{11} \times \rho(\tau)[18]$, и для нормированной временной автокорреляционной функции интенсивности излучения $\eta(\tau)$ получаем

$$
\eta(\tau)=e^{-k_{11}+k_{11} \rho(\tau)}
$$

где $\tau=t_{2}-t_{1}$, а $\rho(\tau)$ - нормированная функция автокорреляции разности фаз $x$ волн. В случае, когда $\tau$ превышает $\tau_{0}$ ( значение времени корреляции величины $x$ ), $\rho(\tau)$ стремится к нулю. Тогда функция $\eta(\tau)$ выходит на постоянный уровень $\eta^{*}$, равный $\exp \left(-k_{11}\right)$, по которому легко можно определить величину $k_{11}$. В работах $[17,19]$ было показано, что в случае, когда разность оптических путей пар волн меньше длины волны $\lambda$ при выделении флуктуационной части интенсивности нормированная автокорреляционная функция $\eta^{\prime}(\tau)$ флуктуаций интенсивности совпадает с $\rho(\tau)$. Следовательно, равны и спектральные функции разности фаз волн и флуктуаций интенсивности. Причем, если функция $\rho(\tau)$ является гауссовой, а разности оптических путей превышают $\lambda$, спектры разностей фаз волн и интенсивности подобны с фактором $k_{11}$.

В работе [17] был поставлен эксперимент по проверке корректности формулы (10). Динамика спеклов авторами создавалась путем перемещения моторизованным транслятором тонкой стеклянной пластины, шероховатость которой была аккуратно измерена оптическим профилометром WYKO NT-1100 с погрешностью измерения высоты 3 нм. Значения $\eta$ находили по изображению участка размером $2 \times 4$ мм, а параметр шероховатости $R_{a}-$ на отрезке длиной 1 мм. Экспериментальная функция $\eta(\tau)$ выходит на постоянный уровень и различие в $R_{a}$ (среднеквадратическое отклонение высот), найденное по динамике спеклов и профилометром, не превышает $6 \%$.

\subsection{3 Динамическая интерференция спекл-полей, возникающая при совмещении изобра- жения двух деформируемых тел}

Задача о динамической интерференции спекл-полей, возникающей при наложении спекловых изображений двух деформируемых тел, теоретически была рассмотрена в работе [9]. В работе использовалась трехмерная модель деформируемого рассеивающего тела (разд. 2.1.1). На рис. 2. приведены основные обозначения теории: два трехмерных деформируемых тела $V_{1}$ и $V_{2}$ одновременно освещаются одним и тем же источником $\mathrm{S}$ когерентного излучения. Два пучка рассеянного излучения, проходя сквозь линзы $D_{1}$ и $D_{2}$, с помощью системы зеркал совмещаются. Картина интерференции наблюдается в точке $q$. Формула, описывающая интенсивности излучения в точке, точно совпадает с выражением (4). Если обеспечить совпадение направлений освещения и наблюдения, то вновь из формулы (4) следует выражение (5). Таким образом, становится возможным определение относительного перемещения точек объектов и по числу периодов интерференции в точке согласно формуле (5). 
open-2CCess journal

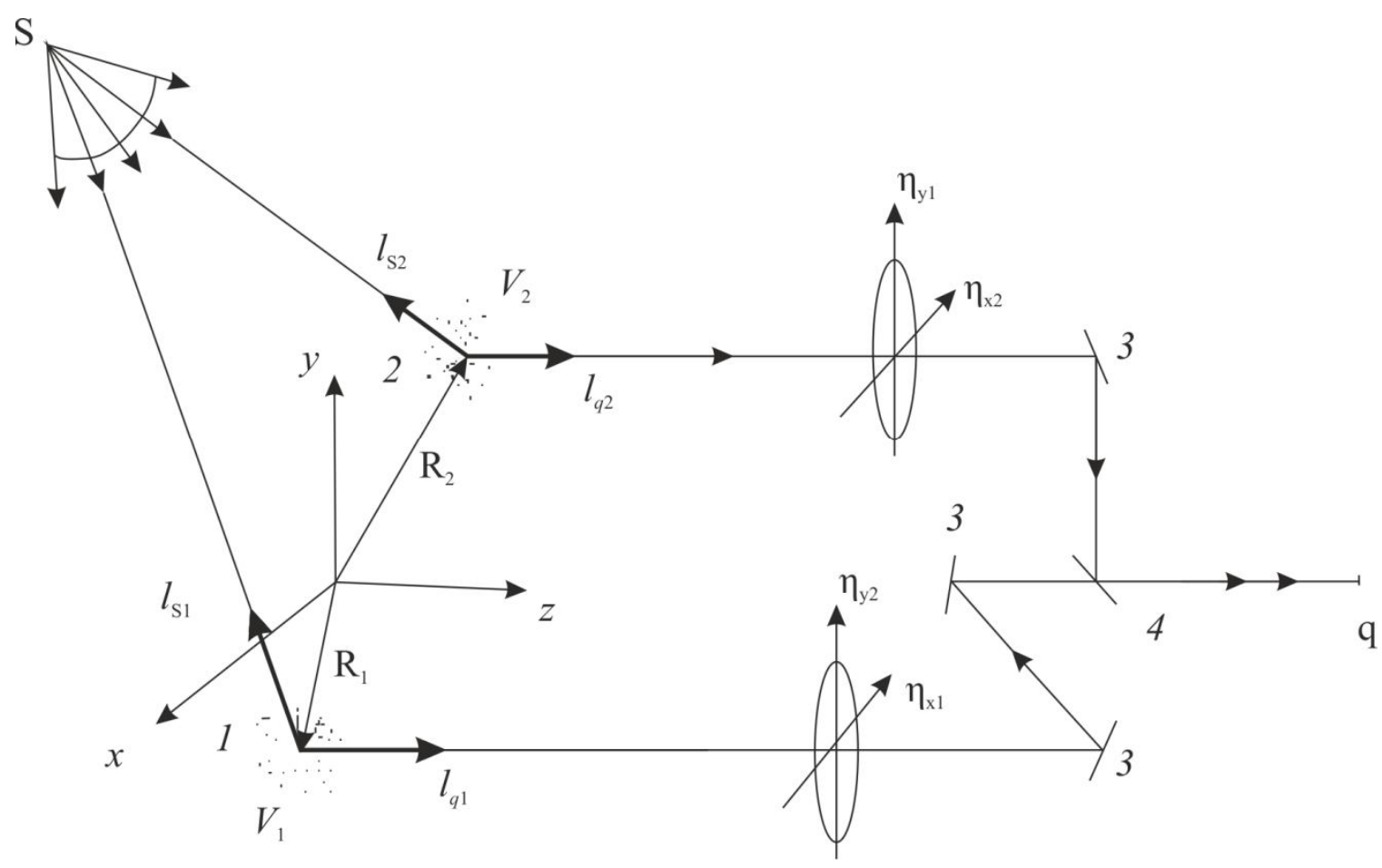

Рис. 2. Система координат и обозначения: 1, 2- объекты; 3 - зеркала; 4 - полупрозрачное зеркало

\section{3 Метод усреднения во времени}

\subsection{1 Теория динамики спеклов в плоскости изображения периодически дерормируемого объекта}

Теория динамики спеклов (разд. 2.2.2) была разработана для однородных в пространстве и стационарных во времени случайных процессов. На практике в значительном большинстве случаях микроскопические процессы, протекающие на структурном уровне (изменяющие разность фаз волн), не являются стационарными. В качестве примеров нестационарных процессов можно указать явления, возникающие при многоцикловой усталости металлов, в клетках живых биологических объектов, и плоском перемещении шероховатой поверхности. При многоцикловой усталости металлов по мере увеличения числа циклов нагружения могут возникать самые различные типы дефектов. В процессе жизнедеятельности клеток изменяются различные параметры, влияющие на длину оптического пути волн. В опыте с шероховатым объектом можно столкнуться с разномасштабностью рельефа поверхности. В указанных примерах возможно наличие различных процессов, протекающих одновременно и с разной скоростью. При анализе подобных процессов зависимости $\eta(\tau)$ не выходят на постоянный уровень, а изменяются сложным образом, плохо воспроизводятся, а интерпретация полученных данных затрудняется.

Для устранения указанных недостатков методика, предложенная в разд. 2.2.2, была усовершенствована. Основная идея модернизации заключалась в использовании усреднения динамики спеклов во времени. Если известно характерное время $\tau_{0}$ изменения разности фаз волн, соответствующее наиболее быстрому процессу, то время усреднения $T_{1}$ регистрируемых оптических сигналов необходимо взять много большим, чем $\tau_{0}$. В этом случае динамика спеклов будет формироваться вследствие протекания более медленных процессов, а интерпретация экспериментальных данных может значительно упроститься.

Задача о динамике усредненных во времени спеклов, возникающей в плоскости изображения периодически деформируемой поверхности, была рассмотрена в работе [19]. Точечные рассеивающие центры, расположенные на поверхности, одновременно участвуют в трех

Vladimirov A. P. / Dynamic speckle interferometry of microscopic and macroscopic processes in deformable media 
типах движения: периодические (по гармоническому закону с периодом $T$ ) и малые поступательные вдоль оси $O X$, а также малые перемещения, случайные во времени и в пространстве. Усредненная по времени интенсивность излучения $\widetilde{I}$ в некоторой точке $\vec{q}$ плоскости изображения регистрируется в течение времени $T_{1}>T$. Предположим также, что случайные перемещения могут возникать только после завершения очередного цикла периодического движения, а в течение времени $T_{1}$ поступательные перемещения по оси $X$ можно считать неизменными. В итоге были получены следующие выражения для $\widetilde{I}(\vec{q})$ и $B_{1,2}\left(t_{1}, t_{2}\right)$ :

$$
\begin{gathered}
\widetilde{I}(\vec{q})=I_{1}+I_{2} e^{-k^{2} \sigma^{2} / 2} \cos (x+\alpha) ; \\
B_{1,2}\left(t_{1}, t_{2}\right)=I^{2} N(N-1) C_{0}^{2} R_{12}\left(u_{x}\right) \cos \left[\left(\left\langle x_{2}\right\rangle-\left\langle x_{1}\right\rangle\right)\right] \times e^{-\frac{1}{2} k_{11}-\frac{1}{2} k_{22}+k_{12}},
\end{gathered}
$$

где $I_{1}, I_{2}, \alpha, C_{0}^{2}-$ константы;

$$
R_{12}\left(u_{x}\right)=\frac{2 x_{s}-u_{x}}{2 x_{s}}
$$

где $2 x_{s}$ - линейное разрешение линзы в направлении оси $O X ; R_{12}\left(u_{x}\right)$ - автокорреляционная функция интенсивности излучения, которая в отсутствие случайных перемещений определяет декорреляцию спекл-поля, вызванную поступательным перемещением поверхности.

В отличие от выражения (9), в формулах (11) и (12) величина $x$, усредненная по времени $T_{1}$, является разностью фаз пар волн. Величина $\sigma^{2}$ в формуле (11) - дисперсия величины $x$.

В выражениях (11) и (12) отсутствует параметр, характеризующий периодические движения поверхности. Это обусловлено тем, что в них фигурирует усредненная по времени интенсивность, которая в отсутствие поступательного перемещения и случайных смещений центров рассеяния не будет изменяться. При этом наблюдатель не будет видеть изменяющееся во времени спекловое изображение поверхности. Когда в малой области поверхности произойдут процессы, приводящие к необратимому смещению центров рассеяния, структура спеклов изменится.

В работе [19] было найдено также выражение для $\widetilde{I}$ в случае, когда в окрестности сопряженной точки на поверхности объекта случайные процессы неоднородны. Предполагалось, что область, размер которой равен разрешению линзы, состоит из двух участков 1 и 2 . Для каждого из участков микроскопические процессы однородны, но параметры, характеризующие изменения оптических путей волн, для разных участков различаются. Выражение для $\widetilde{I}$ имеет следующий вид:

$$
\widetilde{\mathrm{I}}(\overrightarrow{\mathrm{q}})=\widetilde{\mathrm{I}}_{1}+\widetilde{\mathrm{I}}_{2}+2 \widetilde{\mathrm{I}}_{12} \cos [\mathrm{k} \Delta \mu+\theta]
$$

где $\widetilde{I}_{1}$ и $\widetilde{I}_{2}$ - средние по времени интенсивности, формируемые участками 1 и 2 по отдельности; $\widetilde{I}_{12}=I_{0} e^{-\sigma_{1}^{2} / 2-\sigma_{2}^{2} / 2} A_{12} ; I_{0}, A_{12}$ и $\theta-$ константы; $\Delta \mu=\mu_{1}-\mu_{2}$ - разность средних по времени случайных перемещений $\mu_{1}$ и $\mu_{2}$ на участках 1 и 2 соответственно; $\sigma_{1}^{2}$ и $\sigma_{2}^{2}-$ их дисперсии. 
Похожесть формул (11) и (14) имеет вполне определенный физический смысл. Обе формулы устанавливают связь между $\widetilde{I}(\vec{q})$ и случайными перемещениями $u_{n}=\vec{u}_{n}\left(\vec{l}_{s}+\vec{l}_{q}\right)$ центров рассеяния, где $n$ - номер центра рассеяния; $\vec{l}_{s}$ и $\vec{l}_{q}$ - единичные векторы, направленные от объекта к источнику излучения и в точку наблюдения соответственно. Величина $\mu_{1}$ - среднее значение $u_{n}$ на участке 1 , найденное усреднением по участку и по времени; $\mu_{2}$ - то же самое для участка $2 ; \Delta \mu$ - разность средних перемещений. В формуле (11) величина $x$ это усредненные по области и по времени разности перемещений $u_{n}$, взятых для различных пар центров рассеяния. Величину $x$, по-видимому, можно рассматривать как разность перемещений двух точек поверхности, расположенных на некотором «среднем» расстоянии в пределах линейного разрешения линзы.

В целом формулы (9), (10), (11),(12) и (14) можно рассматривать как базу для анализа среднего значения, дисперсии и времени релаксации микроскопических перемещений на поверхности отражающих объектов методом динамической спекл-интерферометрии.

\subsection{2 Макро- и микро-процессы в тонких прозрачных средах и динамика спеклов}

Задача по установлению связи между динамикой фаз волн, зондирующих тонкий прозрачный (фазовый) объект, и динамикой спеклов в плоскости изображения объекта, рассматривалась в работах $[16,17,19,20]$. В $[16,17,19]$ определялась интенсивность излучения, взятая в фиксированный момент времени, а в [20] было получено точное теоретическое решение задачи для усредненных во времени спеклов. Оптическая система, рассмотренная в работе [20], а также принятые обозначения представлены на рис. 3. Когерентное излучение от точечного источника света (1) освещает тонкий прозрачный диффузор (2), состоящий из точечных центров рассеяния. Волны, рассеянные в области размером $2 a_{s}$ в окрестности точки (6) проходят через разные участки фазового объекта и достигают точки (7). Интерференция множества волн формирует в точке (7) случайное значение интенсивности, а в плоскости $q_{x} q_{y}$ - спекл-поле.

Динамика спеклов появляется при изменении фазы волны на величину $\zeta_{j}$, равную

$$
\zeta_{j}=\frac{2 \pi}{\lambda}\left\{\int_{l_{j}}\left[n_{j}(l)-n_{0}\right] d l\right\}=\frac{2 \pi}{\lambda} u_{j}=k u_{j}
$$

где $n_{j}(l)$ - распределение показателя преломления в фазовом объекте вдоль пути $j$-й волны; $l_{j}$ - длина пути $j$-й волны в объекте; $n_{0}$ - показатель преломления в отсутствие фазового объекта, интегрирование ведется вдоль пути волны; $u_{j}$ - оптическая разность хода $j$-й волны в фазовом объекте. 


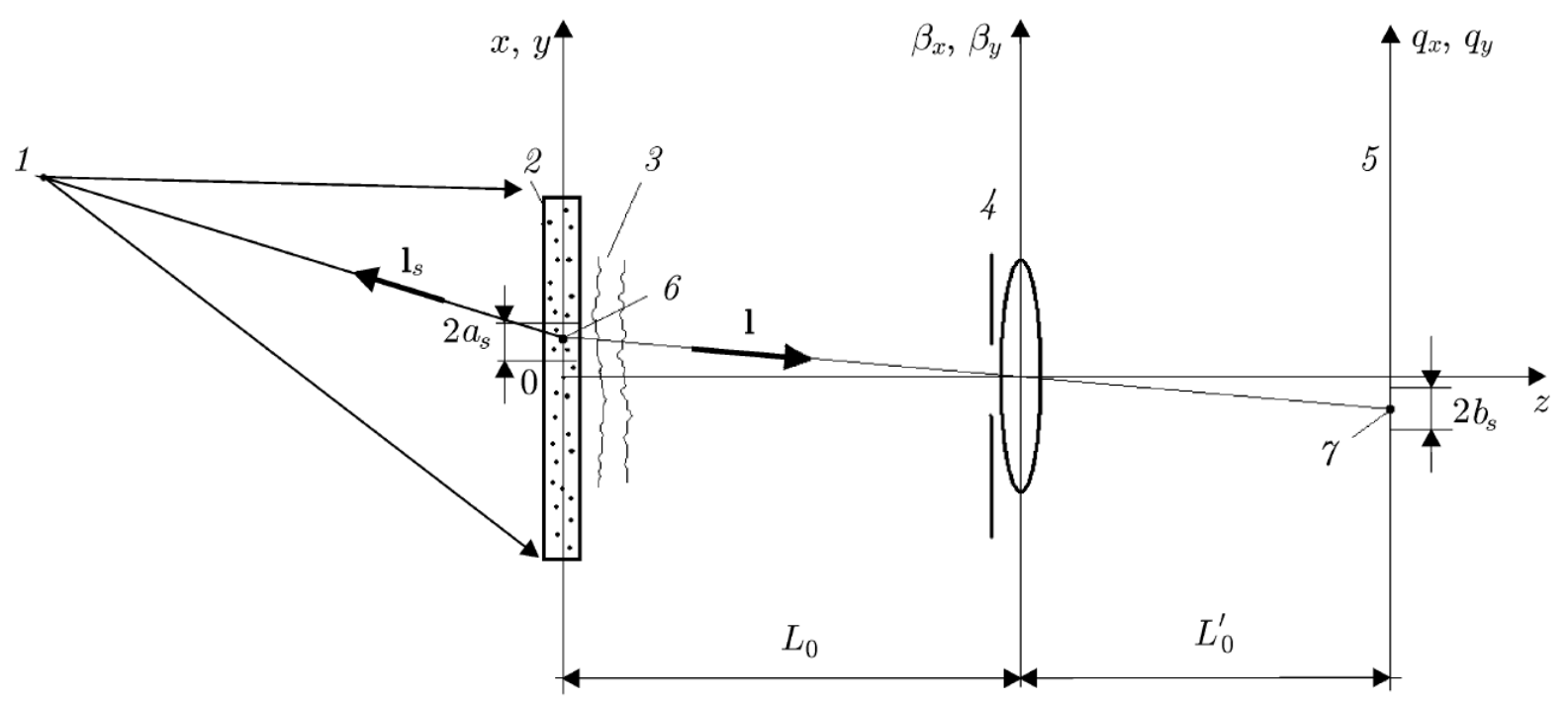

Рис. 3. Оптическая система и обозначения: 1 - освещающий пучок; 2 - диффузор; 3 - фазовый объект; 4 - тонкая линза с диафрагмой; 5 - плоскость изображения; 6, 7 - точки

В результате проведенных расчетов было получено выражение для средней по времени интенсивности излучения $\widetilde{I}$ и временной автокорреляционной функции в точке (7). Формула для $\widetilde{I}$ точно совпадает с выражением (11), а для автокорреляционной функции справедливо выражение (12), если в нем принять, что $R_{12}\left(u_{x}\right)=1$. Совпадение формул является отражением схожести задач о динамике спеклов для отражающего объекта и для пропускающего тонкого объекта. Различие заключается лишь в том, что в первом случае изменение оптической длины пути $j$-й волны возникает при изменении величины $u_{j}=\vec{u}_{j}\left(\vec{l}_{s}+\vec{l}_{q}\right)$, где $\vec{u}_{j}-$ вектор перемещения $j$-го рассеивающего центра, а для фазового объекта определяется изменением показателя преломления.

Из формулы (12) следует, что если время усреднения превышает время корреляции величины $x$, то последний член в экспоненте исчезает и автокорреляционная функция зависит от среднего значения и дисперсии величины $x$. Если теперь значения $u_{j}$ малы по сравнению с длиной волны $\lambda$, то согласно [20] связь между $\widetilde{I}$ и $x$, а также между коэффициентом корреляции $\eta$ спекловых изображений и $k_{22}$ становится линейной:

$$
\widetilde{I} \cong \widetilde{I}_{0}-\widetilde{I}_{f} x, \quad \eta(t)=1-\left(k_{22}(t)-k_{11}\right) / 2
$$

где $\widetilde{I}_{0}$ и $\widetilde{I}_{f}-$ константы; $\eta=B\left(t_{1}, t_{2}\right) / B\left(t_{1}, t_{1}\right) ; t=t_{2}-t_{1}$.

На практике могут встретиться ситуации, когда параметры, находящиеся в формулах (11), (12) и (14) в экспоненте, являются малыми величинами, а расположенные под знаком косинуса, наоборот, относительно большими. В этом случае возможно наблюдение квазипериодического во времени изменения значений $\widetilde{I}$, а также появление отрицательных значений $\eta$. Анализ указанных формул показал, что подобные ситуации могут возникать при относительно больших (пластических) локальных деформациях поверхности отражающих объектов и изменении формы прозрачных тел. 


\section{3. Применение динамической спекл-интерферометрии}

\section{1 Определение поворотов и деформаций участков деформируемых тел по смещению спеклов}

Ямагучи с соавторами в работе [21] сообщили о спекл-датчике малых деформаций, разработанного на основе своих теоретических исследований [8]. Для определения деформации $\varepsilon_{x x}$ поверхность контролируемого объекта освещалась лучом лазера по нормали к поверхности, т.е. по оси $O Z$, а в плоскости $X O Z$ на расстоянии $L_{0}=20$ см симметрично нормали располагали две фотодиодные линейки, которые регистрировали интенсивность спекловых волн, распространяющихся под углом $45^{\circ}$ относительно нормали. Согласно Ямагучи [8], если в выбранной оптической системе с помощью двух линеек определить перемещения спеклов в направлении оси $X$, то их разность будет пропорциональна только величине $\varepsilon_{x x}$. Проведенные эксперименты показали правильность выбранной модели: получено хорошее совпадение значений $\varepsilon_{x x}$, найденных по смещению спеклов и тензодатчиком.

К недостатку этого метода следует отнести возможность определения деформаций только одной малой $\left(\approx 10^{-4}\right.$ м) области объекта. На практике же часто появляется необходимость изучения пространственного распределения деформаций. Возможность такого анализа [14] по смещению спеклов рассмотрена в разд. 2.2.1. Из приведенной формулы (7) следует, что если освещать объект двумя пучками с различными длинами волн $\lambda_{1}$ и $\lambda_{2}$ в единой плоскости падения под одинаковыми углами к нормали (ось $O Z$ ), а наблюдение производить вдоль оси $O Z$, и регистрировать на расстоянии $Z$ от плоскости изображения смещения спеклов $A_{y 1}$ и $A_{y 2}$ от разных источников, то их разность $\Delta A_{y}$ будет связана с деформацией $\varepsilon_{x x}$ в окрестности сопряженной точки по формуле:

$$
\varepsilon_{x x}=\frac{\Delta A_{y}}{2 Z \cos \theta_{y}},
$$

где $\theta_{y}$ - угол между осью $O Y$ и направлением освещения.

В эксперименте был использован образец из вулканизированной резины. Растяжение образца в направление оси $O Y$ осуществляли моторизованным транслятором с шагом 0,2 мкм. Величину $\varepsilon_{x x}$, найденную по формуле (17), сравнивали с величиной $\varepsilon=\Delta l / l_{0}$, где $\Delta l-$ перемещение подвижного захвата; $l_{0}$ - длина рабочей части образца. Авторами была выявлена очень хорошая корреляция между значениями $\varepsilon_{x x}$ и $\varepsilon$.

Формула (7) была использована для разработки методики, позволяющей определять локальные повороты поверхности [13]. При отсутствии поступательного перемещения объекта из формулы следует, что при освещении и наблюдении по нормали и $Z \neq 0$, жесткие повороты поверхности $\omega_{x}=\partial u_{z} / \partial y$ вызовут смещение спеклов по оси $O Y$ на величину

$$
\Delta A_{y}=\omega_{x} 2 Z
$$

Для проверки справедливости данной формулы была собрана экспериментальная установка, объектом исследования выбрана шероховатая пластина, которую вращали вокруг оси $O X$, лежащую на ее поверхности. Полученные данные в целом согласуются с теорией. Как видно из вышеприведенной формулы, имеется положение плоскости наблюдения, где при повороте объекта спеклы не смещаются. В том случае, когда телекамера располагается ближе или дальше от этого положения, на экране наблюдается перемещение спеклов. В этом

Vladimirov A. P. / Dynamic speckle interferometry of microscopic and macroscopic processes in deformable media 
опыте обнаружена линейная зависимость смещения спеклов от угла поворота. Величина перемещения, приходящегося на единицу угла поворота, также линейно зависит от расстояния между линзой и плоскостью наблюдения. Однако тангенс угла наклона этой зависимости, найденный равным $1,54 \pm 0,03$, не согласуется с теоретическим значением - 2 . Положение плоскости наблюдения с нулевым смещением спеклов также несколько отличается от теоретического положения. Авторы объясняют найденные расхождения несовершенством эксперимента.

\section{2 Анализ полей деформационных перемещений по интерференции двух спекл-полей}

Корректность теории, изложенной в разд. 2.2.3, и экспериментальная возможность ее использования для изучения полей перемещений деформируемых тел предсталены в работах $[22,23]$. Схема экспериментальной установки, реализованной в работе [23], приведена на рис. 4. Главной особенностью установки является комбинация трех методов регистрации картин интерференционных полос в плоскости изображения деформируемого объекта: вопервых, классического метода голографической интерферометрии, во-вторых, метода корреляционной спекл-интерферометрии и, в-третьих, нового метода динамической спеклинтерферометрии.

В установке в качестве деформируемого (5) и неподвижного (6) объектов были использованы две одинаковые латунные мембраны диаметром 12 мм, толщиной 200 мкм. Для формирования двух изображений мембран использовалась линза (12) с фокусным расстоянием 100 мм и круглой диафрагмой (11) с диаметром около 0,4 мм. Такая малая диафрагма была необходима для формирования спеклов достаточно больших размеров, для того чтобы минимальный размер спеклов был больше размера отдельного элемента матрицы фотоприемников. Наложение двух спекловых изображений обеспечивали зеркалом (10) и светоделительным кубиком (9).

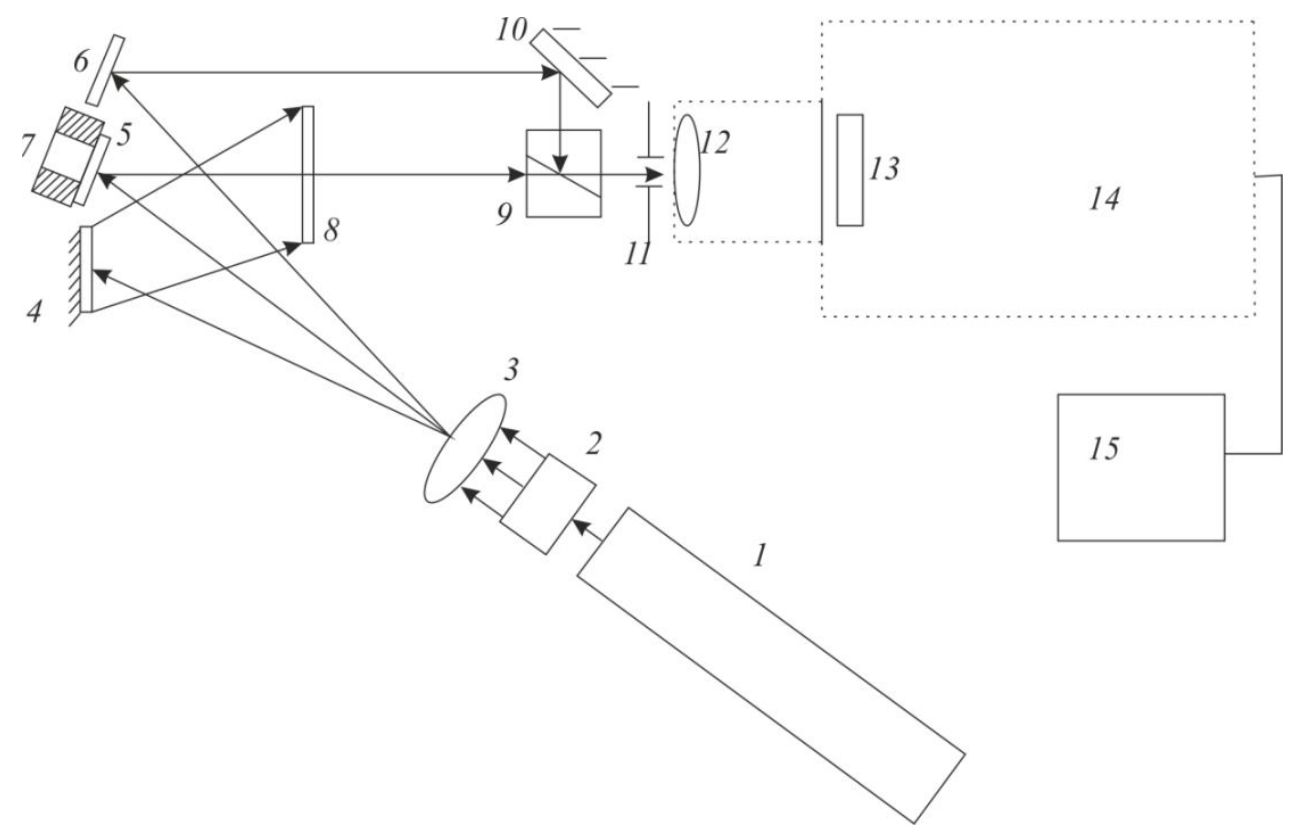

Рис. 4. Схема экспериментальной установки: 1 - лазер; 2 - расширитель луча; 3 - линза; 4 - зеркало; 5, 6- мембрана; 7 - втулка; 8 - фотопластинка; 9 - светоделительный кубик;

10 - зеркало; 11 - диафрагма; 12 - фокусирующая линза;

13 - матрица фотоприемника видеокамеры; 14 - телекамера; 15 - компьютер

В плоскости изображения мембраны 5 располагалась приемная матрица 13 монохромной телекамеры 14. Видеокадры в формате AVI вводились в компьютер 15. Деформацию мембраны 5 осуществляли пьезоэлементом, наклеенным на ее тыльной стороне. На пье- 
зоэлемент подавали плавно увеличивающееся напряжение от нуля до 15 Вольт с типичной скоростью 0,2 B/с. После регистрации в память компьютера динамики интерференции спеклполей, отраженных от объектов 5 и 6 , была зарегистрирована серия двухэкспозиционных голограмм. Первое экспонирование фотопластинки 8 осуществляли при напряжении 0 В, вторые экспозиции - при напряжениях от 4 до 15 Вольт. После химической обработки голограмму возвращали на место экспонирования, освещали ее опорным пучком, при этом пучки, освещающие мембраны, перекрывали. Восстановленное изображение мембраны с интерференционными полосами вводили в память компьютера с помощью той же телекамеры 14 , при этом малая диафрагма удалялась.

Динамика интерференции в области наложения спекл-полей была обработана с помощью специально разработанного программного обеспечения. Программа в каждой пиксели изображения объекта строила зависимость сигнала от времени, затем подсчитывала число периодов видеосигнала. Доли периодов определяли путем линейной временной интерполяции. Затем на изображение мембраны выводили линии равных периодов интерференции.

Сначала сравнивали данные, полученные методами голографической интерферометрии и динамической спекл-интерферометрии. Сравнение линий равных периодов, полученных с помощью программного обеспечения, с картиной полос, введенной в компьютер с двухэкспозиционной голограммы, показало, что при равенстве напряжений, поданных на пьезоэлемент, имеется хорошее сходство картин полос двух методов (рис.5). Некоторая «негладкость» полос нового метода была связана с несовершенством использованного программного обеспечения. В работе [23] приведен график зависимости порядка интерференции в центре мембраны, найденного новым методом, от порядка полосы, найденного методом голографической интерферометрии. Тангенс угла наклона зависимости в пределах погрешностей был равен единице. Имела место отличная корреляция массивов данных, полученных двумя методами.

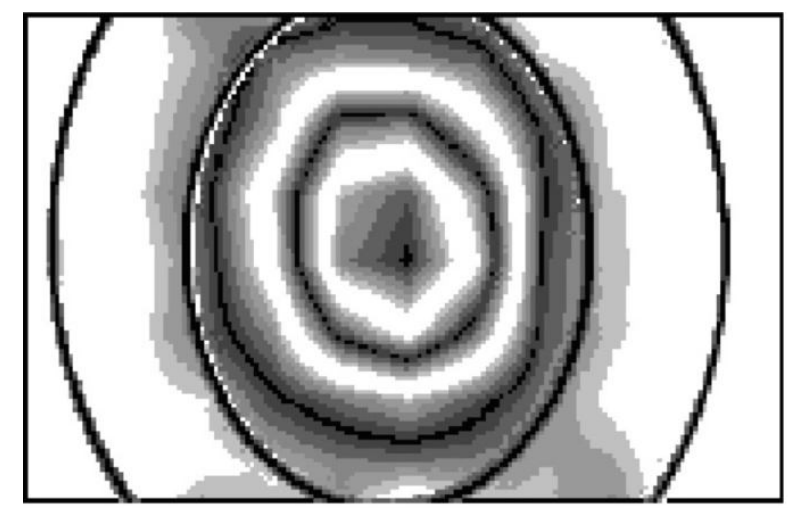

$a$

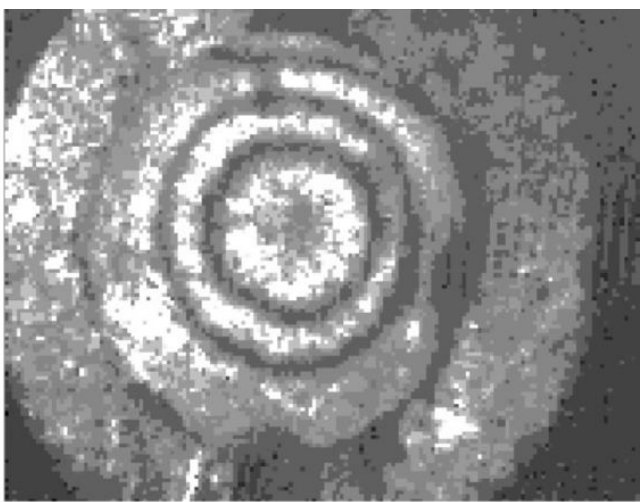

6

Рис. 5. Картины полос, полученных методом динамической спекл-интерферометрии ( $a$ ) и голографической интерферометрии (б)

Кадры видеофильма, соответствующие разным деформациям мембраны, были использованы также для регистрации полос корреляции методом корреляционной спеклинтерферометрии (TV-holography). Сигналы в пикселях начального кадра вычитали из сигналов соответствующих пикселей другого кадра. Было обнаружено, что форма полос корреляции соответствует форме полос, представленных новым методом. В работе [10] приведен график зависимости порядка полосы в центре мембраны, найденного по картинам полос корреляции, от величины $\Delta \mathrm{N}$, подсчитанной новым методом. Тангенс угла наклона линейной

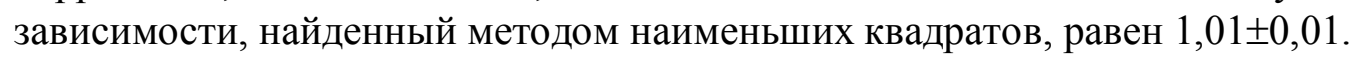

Таким образом, установлено, что имеется совпадение порядков интерференции, а следовательно, и деформационных перемещений, найденных тремя методами: голографической

Vladimirov A. P. / Dynamic speckle interferometry of microscopic and macroscopic processes in deformable media 
интерферометрии, корреляционной спекл-интерферметрии и динамической интерферометрии. Такое совпадение свидетельствует о корректности модели рассеивающего объекта, принятых приближений и расчетов, проведенных в разд. 2.2.3.

Отметим, что в работе [10] обсуждался сдвиговый вариант динамической спеклинтерферометрии, аналогичный свиговому варианту корреляционной спеклинтерферометрии (shearography), позволяющий определять производные от перемещений по координатам.

В работе [10] дано полное разъяснение факту совпадения данных, полученных методами голографической, корреляционной и динамической интерферометрии. В частности, было показано, что в методе двух экспозиций с помощью голограммы регистрируются и восстанавливаются две спекл-модулированные волны. Эти две волны соответствуют двум состояниям поверхности объекта во время экспозиций. Если же мы наблюдаем восстановленное изображение глазом, то два спекл-поля также накладываются на сетчатке глаза. Волны в идентичных спеклах, соответствующих неперемещенной сопряженной части поверхности, точно совпадают по фазе и совокупность таких спеклов формирует полосу нулевого порядка. В то время как (разд. 2.2) при перемещении элемента поверхности в области перекрытия идентичных спеклов возникает сдвиг фаз волн. Если сдвиг фаз равен $\pi$, то в этих областях будет иметь место гашение света, и наблюдатель будет воспринимать совокупность таких областей как темную полосу порядка 0,5. Связь между перемещениями точек поверхности и порядком полос определяем выражением (5). С увеличением величины перемещений область перекрытия в идентичных спеклах уменьшается, а контраст полос падает. Когда величина смещения спеклов превысит его средний размер или произойдет полная декорреляция двух спекл-полей, интерференционные полосы полностью исчезнут.

В новом методе динамической спекл-интерферометрии также имеет место интерференция волн в области перекрытия спеклов. Только в этом случае мы имеем дело с наложением неидентичных спеклов - спеклов от разных объектов. Когда направления освещения объектов и распространения рассеянных волн совпадают, справедлива формула (5), т.е. перемещения поверхности и порядок интерференции связаны таким же образом, как и в методе голографической интерферометрии [5]. В новом методе регистрируются временные периодические изменения интенсивности света, а в методе голографической интерферометрии регистрация полос осуществляется в фиксированный момент времени.

Методы корреляционной и голографической интерферометрии (в настоящее время цифровой вариант последней) активно используются для изучения деформаций тел. Однако недостатки методов ограничивают их применение. Прежде всего, оба метода имеют небольшой диапазон измеряемых перемещений (несколько микрон). Выход за пределы этого диапазона крайне осложняет процесс анализа деформаций в силу плохой различимости интерференционных и корреляционных полос. Метод динамической спекл-интерферометрии позволяет преодолеть указанный недостаток. Уменьшая диаметр точечной диафрагмы линзы, достигаем величины минимального размера спеклов, немного превышающего размера ячейки матрицы фотоприемников. В процессе деформации в конкретной ячейке интенсивность света от одного из спеклов может достигнуть нуля. В этом случае временное квазипериодическое изменение интенсивности прекращается. Тогда мы можем продолжить измерения в соседней ячейке, расположенной в области перекрытия другой пары спеклов. Опыт показал, что такое решение позволяет увеличить диапазон определяемых перемещений до двух порядков.

\section{3 Регистрация ультразвуковых волн}

Ультразвуковые, в том числе и релеевские волны, традиционно применяются для решения различных задач неразрушающего контроля [24]. В тех случаях, когда требуются бесконтактные измерения, применимы методы двойного электромагнитного акустического пре-

Vladimirov A. P. / Dynamic speckle interferometry of microscopic and macroscopic processes in deformable media 
образования (ЭМАП) [24] и интерферометрического [25-29] преобразования акустических колебаний в электрические сигналы. Подобные методики и устройства на их основе важны для определения остаточных напряжений и обнаружения повреждений, влияющих на остаточный ресурс объектов. В работах [26] и [27] были предложены спекл-интерферометрические методики, в которых не требуется предварительной подготовки поверхности. В статье [28] дано подробное описание методики и устройства для регистрации ультразвуковой волны Релея. Показано, что если освещение и наблюдение участков осуществляются перпендикулярно поверхности, то при малых по сравнению с длиной волны перемещениях из формулы (5) для переменной части интенсивности следует, что

$$
I=-I_{12} \times \sin \left\{\varphi_{0}\right\} \times \frac{2 \pi}{\lambda}\left(u_{1}-u_{2}\right)
$$

где $u_{1}$ и $u_{2}$ - соответственно проекции векторов $\vec{u}_{1}$ и $\vec{u}_{2}$ на нормаль. Регистрацию смещения поверхности при последовательном прохождении по освещенным участкам волны Релея осуществляли с помощью фотоприемника, помещенного в область перекрытия спеклов. Данный способ формирования сигнала, пропорционального величине разности $\left(u_{1}-u_{2}\right)$, был реализован в установке, схематически представленной на рис. 6. В качестве источника излучения был использован лазерный модуль 1 , луч лазера направлялся на линзу 2. Линза фокусировала луч лазера на поверхность образца 6 . Диаметр светового пятна на поверхности был равен 40 мкм. После линзы излучение попадало на светоделительную не поляризационную призму 3 , которая разделяла излучение на равные по интенсивности пучки. Вышедшие из призмы 3 лучи попадали на зеркала 4 и 5, которые направляли излучение на поверхность образца 6 по нормали. Освещенные участки поверхности могли располагаться на расстояниях от 5 до 100 мм. Отраженные по нормали пучки зеркалами 4 и 5 направлялись на призму 3, накладывались друг на друга и далее попадали на фотодиод 7. Электрический сигнал с фотодиода поступал на вход усилителя 8 , а затем запоминался осциллографом 9. Преобразователь 10 , используемый для генерации волны Релея, жестко фиксировали относительно образца с помощью специального узла.

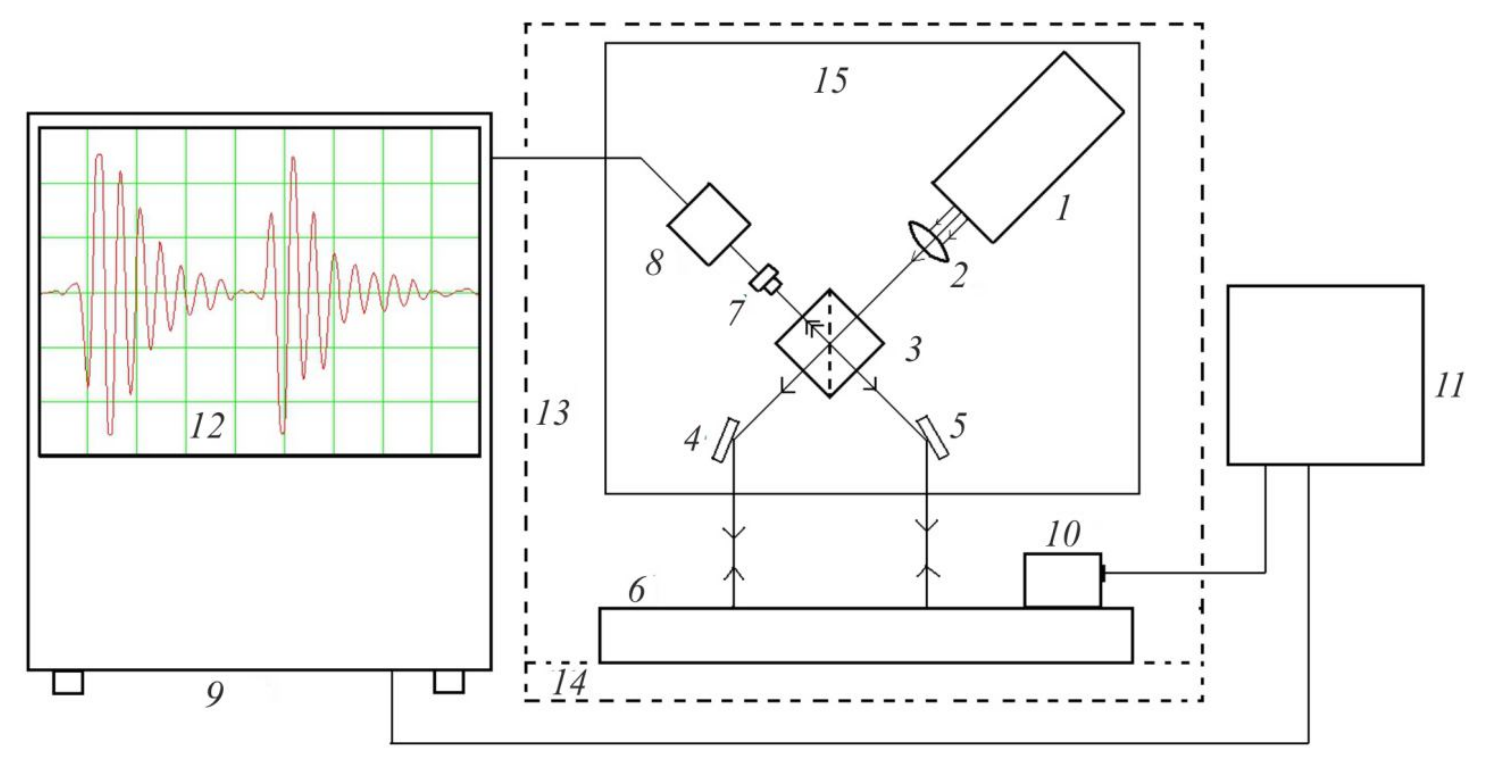

Рис. 6. Схема спекл-интерферометрической установки: 1 - лазер; 2 - линза; 3 - светоделитель; 4, 5 - зеркала; 6 - фиксатор с образцом; 7 - фотодиод; 8 - усилитель; 9 - осциллограф; 10 - преобразователь; 11 - генератор импульсов; 12 - осциллограмма; 13 - плита; 14 - основание; 15 - пластина 
В работе [29] методика была модернизирована. Образец вместе с закрепленным на нем пьезо-преобразователем с помощью механического устройства перемещали относительно оптической системы, тем самым изменяли расстояние $S$ между преобразователем и первым освещенным лазером участком. Это устройство позволяло перемещать образец вдоль его оси с шагом 0,2 мкм. В эксперименте фиксировали величину $\Delta S=S-S_{0}\left(S_{0}\right.$ - начальное значение $S$ ) и время распространения $\Delta t_{1}$ упругой волны от преобразователя к первому освещенному участку (рис. 6). В данной методике второй освещенный участок играет второстепенную роль, формируя пучок для интерференции спекл-полей в области фотоприемника. Скорость волны Релея рассчитывали как тангенс угла наклона зависимости $\Delta S$ от $\Delta t_{1}$.

Рассмотренные методики были использованы в работах [27-29] для изучения корреляции меду скоростью волны Релея и искажениями кристаллической решетки, возникшими в результате термической обработки и пластической деформации металлов.

\section{4 Мониторинг процесса зарождения усталостной трещины без остановки цикличе- ского нагружения}

В работах [30-34] были проведены исследования возможности использования различных физических методов для выявления повреждений при многоцикловой усталости. Подобные исследования, направленные на поиск предвестников макроскопического разрушения, актуальны как с научной, так и с практической точки зрения. Значительный интерес представляют методы, позволяющие изучать накопление усталостных повреждений без остановки циклического нагружения. Так, в работе [34] были изучены особенности выделения тепла и генерации сигналов акустической эмиссии (АЭ) при циклическом деформировании образца из армко-железа. Авторы указали на ряд методических трудностей, возникающих при использовании тепловых эффектов и сигналов АЭ в качестве предвестников усталостного разрушения.

После создания лазеров и обнаружения пятнистой или спекловой структуры когерентного излучения были предприняты многочисленные попытки использовать спеклы для изучения процесса усталости материалов [35-37]. Однако предложенные методы на первых порах не нашли широкого применения из-за их значительной трудоемкости и немонотонного характера изменения сигналов. Дальнейшее развитие спекл-интерферометрии применительно к процессам усталостного разрушения [38-40] показало, что метод корреляции усредненных во времени спекловых изображений может быть использован для изучения усталости материалов без остановки циклического нагружения.

В разд. 2.3.1 было показано, что отличительной особенностью метода усреднения спеклов является выбор времени экспозиции $\tau_{0}$, используемой в эксперименте телекамеры равным или кратным периоду $T$ циклического нагружения. При $\tau_{0}=T$ элемент матрицы фотоприемников телекамеры откликается на усредненную за промежуток времени $T$ интенсивность излучения. Если же в объекте отсутствуют необратимые процессы, то при следующих интервалах времени длительностью $T$ оцифрованные значения сигналов будут неизменными. В случае, когда в процессе колебания в объекте начинаются необратимые процессы, влияющие на микрорельеф поверхности, спекл-поле, а за ним и регистрируемые сигналы, будут изменяться.

Этот подход впервые был успешно апробирован в работе [38]. В ней при линейном разрешении линзы в 60 мкм были обнаружены квазипериодические изменения интенсивности излучения и близкая к линейной связь между коэффициентом корреляции спекловых изображений и числом циклов нагружения. В работах $[39,40]$ была исследована корреляция между изменениями рельефа поверхности и ее спекловых изображений при зарождении, старте и распространении усталостной трещины. Объект исследования - призматический образец размером $10 \times 10 \times 55$ мм из низкоуглеродистой стали 09Г2С. С целью локализации места возможного зарождения усталостной трещины на образец был нанесен острый

Vladimirov A. P. / Dynamic speckle interferometry of microscopic and macroscopic processes in deformable media 
V-образный надрез типа Шарпи глубиной 2 мм и радиусом в вершине 0,25 мм. После фрезерования и тонкой шлифовки с последующим отжигом в вакууме наблюдаемая сторона некоторых образцов подвергалась полировке для создания хорошей зеркальной поверхности с параметром шероховатости $R_{a}$ в диапазоне $1 \div 50$ нм.

Циклическое нагружение образца проводили на высокочастотной резонансной испытательной машине MIKROTRON (RUMUL) по схеме трехточечного изгиба с максимальным усилием цикла 1,2 кН при частоте нагружения $\approx 100$ Гц, с коэффициентом асимметрии цикла $\mathrm{R}=0,1$.

Для регистрации спекл-полей была использована оптическая система, схема и геометрические размеры которой представлены на рис.7. Оптическая установка размещалась на платформе испытательной машины. Объект 4 освещали пучком 2 от лазерного модуля 1 типа KLM-H650-40-5 с длиной волны 0,65 мкм и мощностью 40 мВт. При испытании образцов с зеркальной поверхностью в освещающий пучок вводили матовое стекло 3. Картину спеклов регистрировали в плоскости изображения образца. Увеличение, формируемое оптической системой, составляло 0,7 крат. Размер диафрагмы у линзы 5 подбирали таким образом, чтобы минимальный размер спеклов был несколько больше размера фотоэлемента матрицы фотоприемников (6) телекамеры. В экспериментах использовалась монохромная телекамера ВИДЕОСКАН-415M-USB с матрицей, содержащей $782 \times 582$ фотоэлемента размером 8,3×8,3 мкм. Выбранное время экспозиции телекамеры, составляющее 0,5 сек, соответствовало 50 циклам нагружения. Регистрацию кадров спекловых изображений в формате ВМР осуществляли через 1000 - 2500 циклов нагружения после стабилизации резонансной частоты испытательной машины. Изменение спекл-полей определяли с помощью коэффициента корреляции $\eta$ двух 8-битных цифровых изображений одинакового размера. Цифровые изображения представляли собой двумерные матрицы, соответствующие одному участку кадра в начальный момент времени $t_{1}$ и текущий момент времени $t_{2}$ при значениях числа циклов нагружения $N_{1}$ и $N_{2}$ соответственно. Значения $\eta$ находили по формуле

$$
\eta=\frac{\frac{1}{n m} \sum_{i=0}^{n-1} \sum_{j=0}^{m-1}\left(A_{i j}-\bar{A}\right)\left(B_{i j}-\bar{B}\right)}{\left(\frac{1}{n m} \sum_{i=0}^{n-1} \sum_{i=0}^{m-1}\left(A_{i j}-\bar{A}\right)^{2}\right)^{1 / 2}\left(\frac{1}{n m} \sum_{i=0}^{n-1} \sum_{i=0}^{m-1}\left(B_{i j}-\bar{B}\right)^{2}\right)^{1 / 2}},
$$

где $i, j$ - номера элементов (пикселей) строки и номера строк матрицы соответственно; $n, m$ - число пикселей строки и число строк матрицы; $A_{i j}$ - числовое значение пикселя с номерами $i$ и $j$ при $t_{1} ; B_{i j}$ - числовое значение этого пикселя в момент времени $t_{2} ; \bar{A}-$ среднеарифметическая величина числовых значений элементов матрицы при $t_{1} ; \bar{B}-$ среднеарифметическая величина числовых значений элементов матрицы в момент времени $t_{2}$.

При достижении 50 000, 100000 и 110000 циклов нагружения образец снимали с испытательной машины для регистрации профилей поверхности и определения среднеарифметического отклонения высот рельефа на выбранном участке. Исследование поверхности образцов проводили на оптическом профилометре WYKO NT-1100 и с помощью зондового микроскопа NTEGRA Maximus (NT-MDT) с погрешностями измерения высоты 3 и 0,1 нм соответственно. 
optri-acCeSs journal

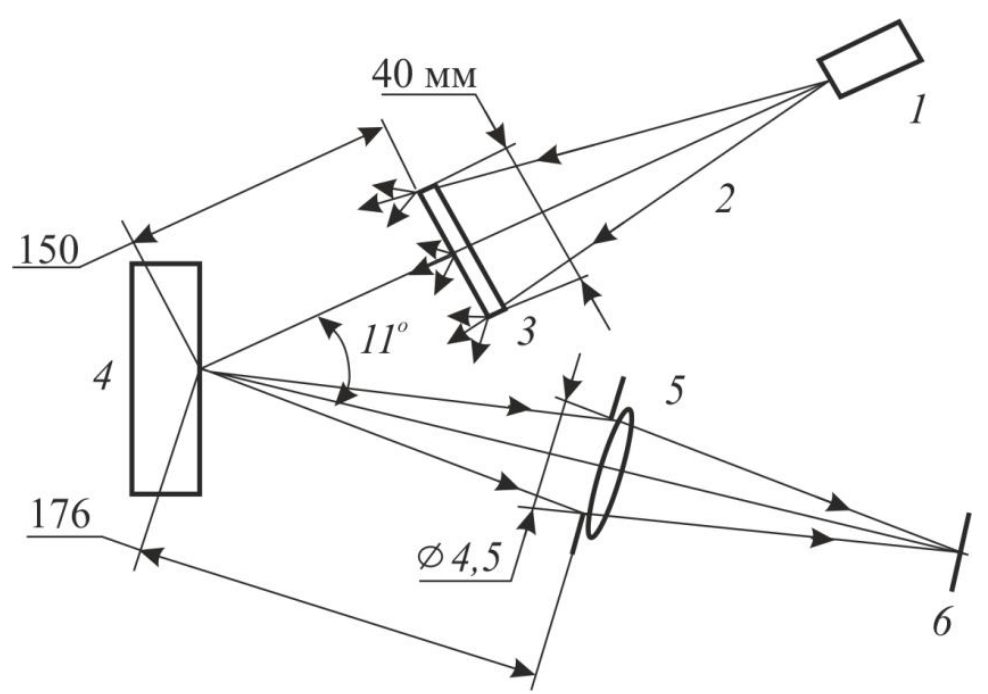

Рис. 7. Схема оптической установки: 1 - лазерный модуль; 2 - освещающее излучение; 3 - матовое стекло; 4 - образец; 5 - линза с диафрагмой; 6 -матрица фотоприемников телекамеры

На рис. 8 приведены взятые из работы [39] трехмерные профили поверхности образца на разных этапах циклического деформирования. Для сравнения на рис. 9 показано распределение величины $\eta$ при тех же циклах нагружения (значения $\eta$ определяли на участках размером $8 \times 8$ пикселей). На рис. 8 видно, что вблизи надреза образовалась зона пластической деформации в виде впадины диаметром $\approx 300$ мкм и глубиной около 0,5 мкм. Кроме того, в вершине надреза появилась дополнительная зона размером примерно $30 \times 40$ мкм, рельеф которой существенно отличается от окружающего и состоит из хаотично расположенных выступов. Рельеф поверхности в этой зоне характеризуется совокупностью участков диаметром примерно 5-10 мкм, а перепад высот достигает сотен нанометров. Приблизительно на середине этого участка формируется и стартует усталостная трещина.

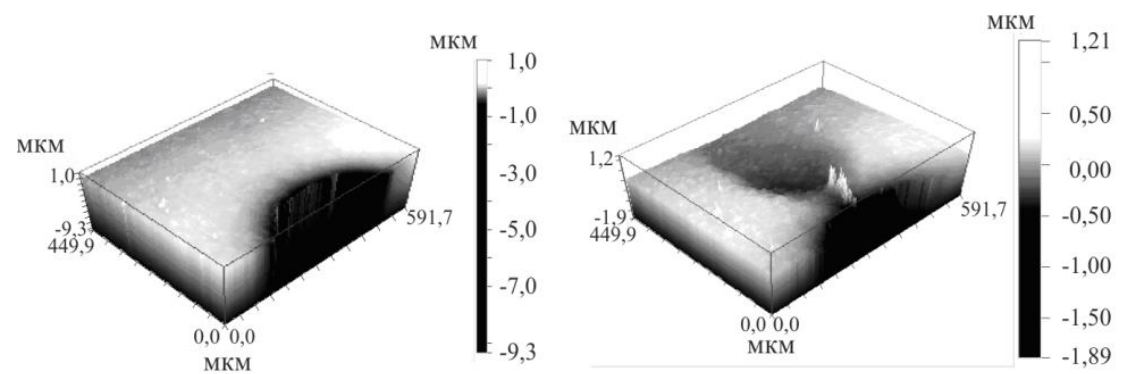

б

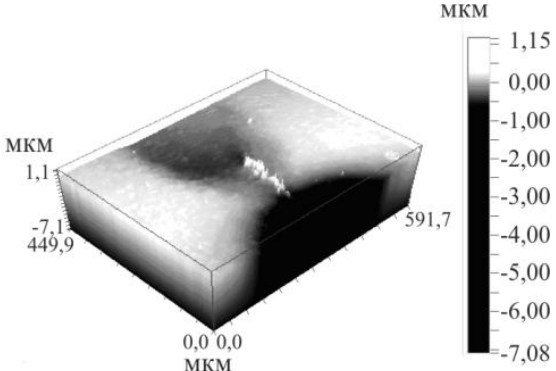

B

Рис. 8. Трехмерные профили поверхности вблизи надреза: $a-\mathrm{N}=50000 ; \sigma-\mathrm{N}=100$ 000;

$$
\text { в- } \mathrm{N}=110000
$$




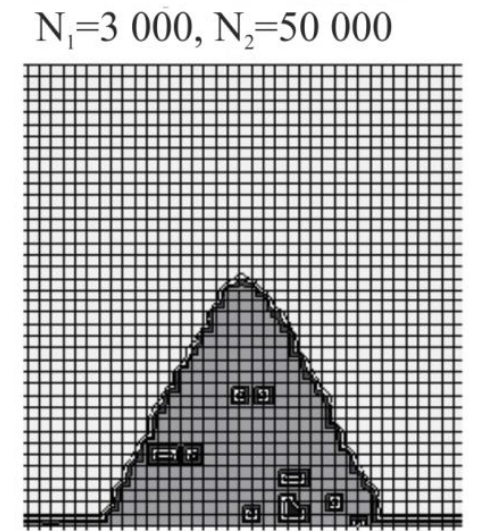

$a$

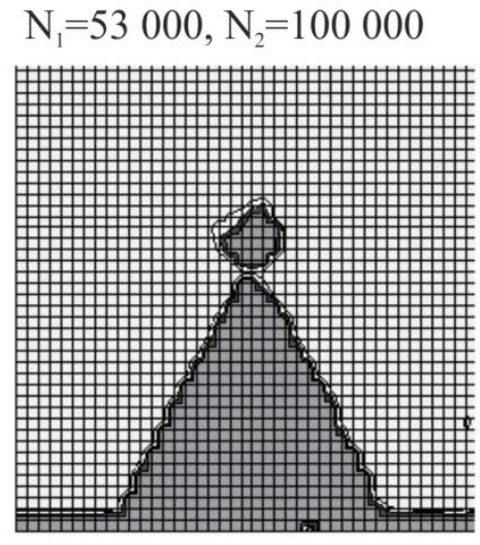

6

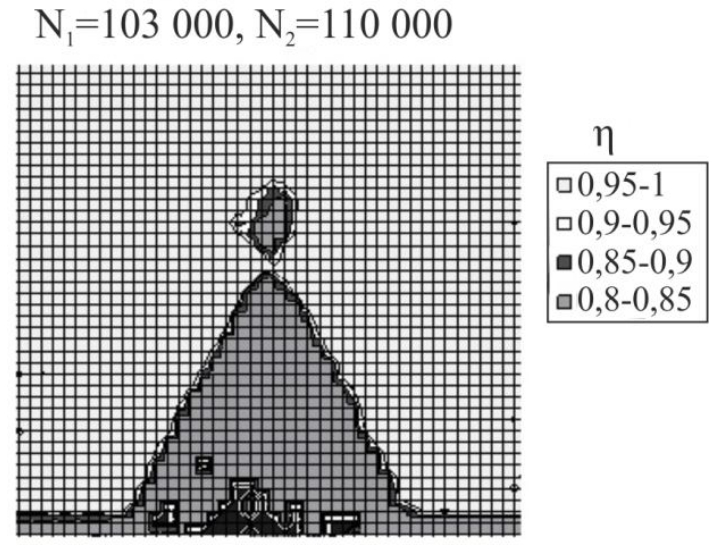

B

Рис. 9. Распределения величины $\eta$ на разных этапах испытания образца

Сопоставление динамики спекл-полей и рельефа поверхности в промежутке от 50000 до 100000 циклов нагружения показало, что изменения величины $\eta$ вызваны четырьмя факторами:

- $\quad$ малыми поступательными перемещениями объекта, по-видимому, связанных с появлением и постепенным накоплением остаточных деформаций. Такие смещения вызывали уменьшение величины $\eta$ от единицы до 0,99 ;

- небольшими изменениями шероховатости поверхности в пределах впадины, приводящими к увеличению значения параметра $R_{a}$ на десятки нанометров при уменьшении значения $\eta$ примерно на величину 0,05 ;

- $\quad$ хаотическими изменениями высоты рельефа на сотни нанометров в зоне зарождения усталостной трещины, приводящими к падению значения $\eta$ в этой зоне до величины $0,7-0,8$;

- $\quad$ детерминированным формированием впадины глубиной порядка $1 \mu \mathrm{m}$, при котором коэффициент корреляции $\eta$ резко уменьшается до отрицательных значений, достигающих величины $(-0,5)$ на изображении наиболее крутых склонах впадины.

На основе исследований, проведенных в работах $[17,18,38-40]$, можно сделать вывод о том, что разработана новая спекловая методика, позволяющая в процессе циклического нагружения без его остановки находить области поверхности образца, где появляются первые признаки необратимых процессов. Методика позволяет контролировать изменение размеров таких областей вплоть до появления и старта усталостной трещины. Использование этой методики в сочетании с другими методами изучения свойств материалов открывает перспективы выявления механизмов усталостных повреждений и их накопления. Методика перспективна с точки зрения создания физических моделей многоцикловой усталости материалов, а на их базе - методов оценки остаточного ресурса элементов конструкций.

\section{5 Контроль активности жнивых клеток}

\subsection{1 Анализ активности ансамбля клеток}

В настоящее время динамика спеклов успешно применяется для изучения процессов в биологических объектах [41], для исследования динамики кровотока [42]. Вместе с тем логика развития оптики спеклов и нужды практики выдвигают задачу изучения микроскопических процессов, протекающих на структурном уровне в клетках человека. В частности, в медицине проблема выбора лекарства для конкретного пациента выдвигает задачу изучения

Vladimirov A. P. / Dynamic speckle interferometry of microscopic and macroscopic processes in deformable media 
процессов в клетках и в их мембранах. Поскольку на структурном уровне свойства биологических сред случайны, то при прохождении волн через различные участки клетки, их фаза также случайным образом изменяется во времени. Вследствие этого изменение интенсивности излучения в точке наблюдения становится случайным процессом.

Методические разработки автора в области динамической спекл-интерферометрии деформируемого твердого были успешно использованы им при изучении живых клеток. Принципиальная возможность создания прибора для изучения процессов в живых клетках основана на том, что у человека как замкнутой биологической системы с возрастом функционирование мембран всех клеток становится примерно одинаковым. Поскольку многие болезни людей прямо или косвенно связаны с нарушением функционирования мембран клеток, изучение процессов, происходящих в клетках-свидетелях, позволяет выявить эти нарушения и подобрать средства для их исключения.

Теоретической базой для создания такой методики могут быть закономерности, рассмотренные в разделе 2.3.2, где приводятся соотношения, связывающие параметры оптических путей в тонких биологических объектах и результирующих спеклов в плоскости их изображения. После успешной проверки в работе [16] корректности формулы (12), в работе [43] была исследована и продемонстрирована возможность применения этой теории для изучения активности монослоя клеток, культивированных на прозрачной подложке. Подложка с клетками, помещенная в прозрачную кювету с питательной средой, в качестве объекта исследования устанавливалась в оптическую систему (рис.3). Было установлено, что зависимость $\eta(\tau)$ для клеток в питательном растворе, а также для питательного раствора без клеток, через 5-8 секунд (время релаксации) выходит на постоянный уровень $\eta^{*}$. По этим двум значениям $\eta^{*}$ находится величина среднеквадратического отклонения $\sigma_{u}$ разности оптических путей $\Delta u$ пар волн в клетках. Как для питательного раствора, так и для клеток в растворе время релаксации с увеличением температуры линейно уменьшается. Классические культуральные методы доказали, что скорости метаболических процессов в клетках линейно зависят от температуры. Поэтому было предложено использовать величину $\sigma_{u}$ в качестве параметра, характеризующего активность ансамбля клеток.

В работе [44] было показано, что при использовании метода усреднения спеклов во времени (разд. 2.3.2), воспроизводимость результатов высокая. В работе [44] изучался процесс изменения активности клеток при воздействии вирусов простого герпеса. Было установлено, что изменение активности можно обнаружить уже через 10 минут после начала измерений. Это время во много раз меньше времени, необходимого для обнаружения наличия герпеса в клетках традиционными методами.

В статье [45] впервые по аналогичной методике изучалась активность клеток, осажденных на прозрачную подложку сразу после их размораживания. Размороженные клетки, в отличие от культивированных, постоянно находились в двумерном движении и взаимодействии друг с другом. Проведенное исследование показало, что если для определения величины $\eta$ по формуле (19) выбирается участок поля зрения, содержащий от 4 до 200 клеток, то зависимости $\eta(t)$ примерно через полчаса после размораживания выходили на постоянный уровень $\eta^{*}$. Такая асимптотическая зависимость наблюдалась для разных участков поля зрения. Коэффициент множественной корреляции для четырех зависимостей $\eta(t)$, взятых на разных участках, а также при регистрации их последовательно друг за другом, находился в пределах от 0,8 до 0,9 .

\subsection{2 Изучение внутриклеточных процессов}

В статье [46] представлен спекл-интерферометр для изучения внутриклеточных процессов по методике, рассмотренной в предыдущем разделе. Объекты исследования - отдель-

Vladimirov A. P. / Dynamic speckle interferometry of microscopic and macroscopic processes in deformable media 
open-recess journal

ные клетки, осажденные на стеклянную пластину после их размораживания. Исследовались как изолированные клетки, так и находящиеся в монослое (рис.10).

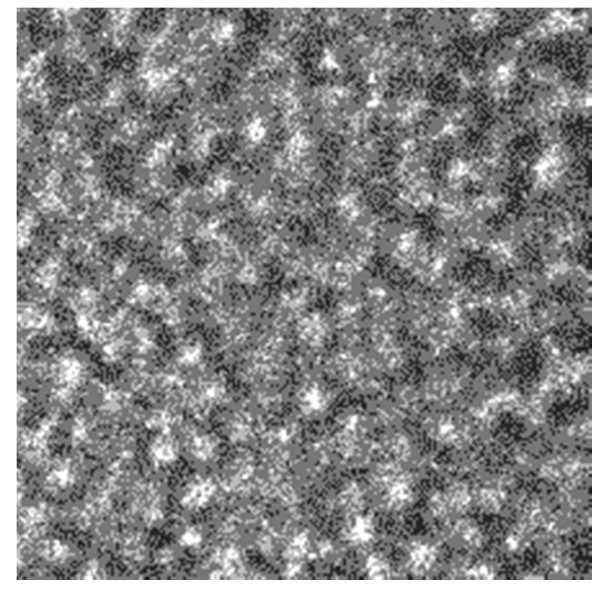

Рис. 10. Типичный фрагмент спеклового изображения клеток

Просмотр фильма, составленного из зарегистрированных кадров, показал, что большая часть клеток находится в непрерывном движении. Были выбраны клетки неподвижные с точки зрения наблюдателя. Анализ зависимостей $\widetilde{I}(t)$ и $\eta(t)$, найденных вне и внутри изображения такой клетки, показал, что методика различает процессы, протекающие в этих областях. В частности, было обнаружено, что изменения $\widetilde{I}$ в пространстве и во времени независимы, а величина $\widetilde{I}$ в центре клетки значительно выше, чем на периферии. Факт существенного различия величины $\widetilde{I}$ в центре и на периферии авторы объясняют тем, что на периферии имеют место более сильные изменения величины $\sigma$, фигурирующей в формуле (11). Из этой формулы следует, что при увеличении $\sigma$ значение $\widetilde{I}$ уменьшается.

Кроме того, было обнаружено, что в зависимостях $\eta(t)$, найденных путем усреднения по многим клеткам, значения $\eta$ уменьшаются до положительных значений $0,1-0,3$. В отличие от этого, для участков внутри клетки величина $\eta$ может принимать и отрицательные значения. Как было отмечено при обсуждении теории в разделе 2.3.2, появление отрицательного значения можно объяснить изменениями среднего значения разности оптических путей волн, походящих через участки, размеры которых равны линейному разрешению линзы. Из формулы (12) следует, что если по какой-либо причине указанная разность, входящая в аргумент косинуса, превысит четверть длины волны, то величина $\eta$ принимает отрицательное значение. По-видимому, появление отрицательного значения величины $\eta$ указывает на изменение формы клетки из-за ее деления или перемещения. На это же указывает и тот факт, что в монослое культивированных клеток, где отсутствуют возможности перемещения и деления клеток, значения $\eta$ уменьшаются с единицы до $0,7-0,8$.

Таким образом, для изучения микроскопических процессов, протекающих внутри клеток, желательно использовать тесно расположенные культивированные клетки не способные к перемещению. В этом случае в формуле (15) влиянием толщины клетки $l$ на длину пути $u$ можно пренебречь, при этом изменение длины пути зондирующих волн будет происходить исключительно вследствие изменения показателя преломления среды. Известно, что показатель преломления $n$ связан с характеристиками среды формулой Лоренц-Лоренца:

$$
\frac{n^{2}-1}{\rho\left(n^{2}+1\right)}=\bar{r},
$$

Vladimirov A. P. / Dynamic speckle interferometry of microscopic and macroscopic processes in deformable media 
где $\rho$ - плотность среды, а $\bar{r}$ - ее удельная преломляющая способность. Для многокомпонентных сред величина $\bar{r}$ равна произведению удельной преломляющей способности отдельных веществ на их относительную концентрацию. Следовательно, изменение показателя преломления в клетках может быть вызвано либо изменением состава среды вследствие процессов массопереноса, либо плотности. Для регистрации изменения последней необходимо проводить измерения на временных интервалах, существенно отличающихся от времени релаксации величины $u$, обусловленной массопереносом веществ. В этом случае изменения интенсивности излучения будут связаны с вариациями плотности. Поскольку в клетках протекают необратимые процессы, связанные с выделениями и поглощениями тепла, сопровождающиеся локальными изменениями температуры, а следовательно, и плотности, то временной спектр флуктуации интенсивности излучения в этом случае является фактически энергетическим спектром химических реакций в контролируемой области клетки.

Известно, что время релаксации процессов, протекающих в мембранах клеток, находятся в микросекундном диапазоне [47]. Поэтому с целью изучения процессов в мембранах клеток, а также особенностей метаболических процессов внутри отдельных клеток, направлением дальнейших исследований может быть модернизация методики по значительному расширению временного диапазона регистрируемых сигналов.

\section{4. Заключение}

В настоящей статье рассмотрена связь между макроскопическими перемещениями, деформациями, поворотами рассеивающих тел, с одной стороны, и смещениями и изменениями спекловой структуры рассеянного излучения - с другой. Показана связь между случайными изменениями фаз волн, вызванными микроскопическими процессами, протекающими на структурном уровне в отражающих и прозрачных средах, и динамикой спекловых изображений. Рассмотрена динамическая интерференция двух спекл-полей, возникающая в процессе деформации рассеивающих сред.

Показано, что перемещения, деформации и повороты участков тел целесообразно определять по смещению спеклов. В частности, если одновременно определять смещения спеклов в разных местах свободного пространства, то можно найти значения компонент вектора перемещения, тензоров деформаций и поворота одного малого участка поверхности. В то время как для анализа полей деформаций и поворота необходимо определять перемещения спеклов в плоскости, отстоящей на некотором расстоянии от плоскости изображения объекта.

В работе приведены примеры использования динамической интерференции двух спекл-полей для регистрации ультразвуковых колебаний шероховатой поверхности и анализа полей деформационных перемещений.

Детально описан оригинальный авторский метод, основанный на усреднении спеклов во времени. Показано, что путем регистрации параметров, характеризующих пространственно-временную динамику спеклов, можно определять средние значения, дисперсию и время корреляции разности путей пар волн, зондирующих объект. Показано также, что при изучении многоцикловой усталости и реакции живых клеток на внешние воздействия применение метода позволяет получать надежные и хорошо воспроизводимые результаты. Метод позволяет в процессе циклического нагружения, без его остановки, обнаруживать области, где возникают первые признаки необратимых процессов, контролировать размеры этой области, фиксировать старт усталостной трещины. Оптическая методика в комбинации с другими известными подходами может быть использована для моделирования усталостных процессов, разработки датчиков многоцикловой усталости и аппаратуры контроля остаточного ресурса деталей.

Vladimirov A. P. / Dynamic speckle interferometry of microscopic and macroscopic processes in deformable media 
Все вышеизложенное позволяет сделать вывод о перспективности использования методов динамической спекл-интерферометрии для изучения процессов в деформируемых средах.

\section{Благодарность}

Статья подготовлена при поддержке проектов УрО РАН № 15-15-1-52, №15-10-1-22 и № 15-7-1-20.

Работа выполнена с использованием оборудования ЦКП «Пластометрия». Автор благодарит руководителей и сотрудников Института машиноведения УрО РАН, НОЦ НАНОТЕХ УРФУ, Екатеринбургского НИИ вирусных инфекций за поддержку проводимых автором исследований.

\section{Литература}

1. Anisimov I. V., Kozel S. M., Lokshin G. R. Space-time statistical properties of coherent radiation scattered by a moving diffuse reflector // Optics and Spectroscopy. - 1969. - Vol. 27, iss. 3. - P. 483-491.

2. Yoshimura T. Statistical properties of dynamic speckles // Journal of the Optical Society of America A. - 1986. - Vol. 3, no. 2. - P. 1032-1054.

3. Veselov L. M., Popov I. A. Information properties of a time-varying speckle pattern // Optics and Spectroscopy. - 1993. - Vol. 74, iss. 6. - P. 685-686.

4. Ruth B., Haina D., Waidelich W. Vibration analysis by speckle counting // Optica Acta: International Journal of Optics. - 1983. - Vol. 30, iss. 6. - P. 841-848. - DOI: 10.1080/713821265.

5. Aleksandrov E. B., Bonch-Bruevich A. M. Investigation of Surface Strains by the Hologram Technique // Soviet Physics-Technical Papers. - 1967. - Vol. 12. - P. 258-265.

6. Leendertz J. A. Interferometric displacement measurement on scattering surfaces utilizing speckle effect // Journal of Physics E: Scientific Instruments. - Vol. 3, no. 3. - P. 214-218. DOI: $10.1088 / 0022-3735 / 3 / 3 / 312$.

7. Vladimirov A. P., Mikushin V. I. Interferometric determination of vector components of relative displacements: theory and experiment // Saratov Fall Meeting '98: Light Scattering Technologies for Mechanics, Biomedicine, and Material Science, 38: proc. SPIE. - 1999. - Vol. 3726. - P. 38-43. DOI: $10.1117 / 12.341416$.

8. Yamaguchi I. Speckle displacement and decorrelation in the diffraction and image fields for small object deformation // Optica Acta: International Journal of Optics. - 1981. - Vol. 27, iss. 10. - P. 1359-1376. - DOI: 10.1080/713820454.

9. Владимиров А. П. Динамическая спекл-интерферометрия деформируемых объектов: дис. ... доктора техн. наук : 05.11.13. - Екатеринбург, 2002. - 393 с.

10. Владимиров А. П. Динамическая спекл-интерферометрия деформируемых тел. - Екатеринбург : УрО РАН, 2004. - 241 с.

11. Vladimirov A. P., Udartsev E. V. The second-order speckle mechano-optical effect: theory and experiment // Saratov Fall Meeting 2002: Laser Physics and Photonics, Spectroscopy, and Molecular Modeling III; Coherent Optics of Ordered and Random Media III, 99: proc. SPIE. - 2003 Vol. 5067. - P. 99-106. - DOI: 10.1117/12.518491.

12. Vladimirov A. P., Mikushin V. I., Lisin A. L. Optical method of determining the components of the relative displacement vector // Technical Physics Letters. - 1999. - Vol. 25, iss. 24. P. 1008-1010.

13. Vladimirov A. P., Popov D. O. Rigid Rotations of a plate and the related speckle displacements in the image plane // Technical Physics Letters. - 2003 - Vol. 29, iss. 10. - P. 855-857.

14. Попов Д. О., Владимиров А. П. Методика определения деформаций по смещениям спеклов // Ресурс и диагностика материалов и конструкций: тезисы докладов IV Российской научно-технической конференции. - Екатеринбург, 2009. - С. 51.

Vladimirov A. P. / Dynamic speckle interferometry of microscopic and macroscopic processes in deformable media 
15. Wolf E. Intensity fluctuations in stationary optical fields // Philosophical Magazine. - 1957. - Vol. 2, iss. 5. - P. 351-354. - DOI: 10.1080/14786435708243824.

16. Vladimirov A. P., Druzhinin A. V., Malygin A. S., Mikitas K. N. Theory and calibration of speckle dynamics of phase object // Proc. SPIE. - 2012. - Vol. 8337. - P. 8337OC: 1-15. DOI: $10.1117 / 12.924800$.

17. Vladimirov A. P. Dynamic speckle interferometry of the microscopic processes // Proc. SPIE. - 2012. - Vol. 8413. - P. 841305: 1-6. - DOI: 10.1117/12.2184567.

18. Пугачев В. С. Теория случайных функций. М : Физматгиз, 1962. - 884 с.

19. Vladimirov A. P. Time-average dynamic speckle interferometry // AIP Conf. Proc. - 2014. Vol. 1600. P. 237-242. - DOI: 10.1063/1.4879588.

20. Vladimirov A. P. Dynamic speckle interferometry of microscopic processes in thin biological objects // Radiophysics and Quantum Electronics. - 2015. - Vol. 57, iss. 8. - P. 564-576. DOI: $10.1007 / \mathrm{s} 11141-015-9540-2$.

21. Yamaguchi I., Takemori T., Kobayachi K. Stabilized and accelerated speckle strain gauge // Proc. SPIE.1989. - Vol. 1162. - P. 187-200. - DOI: 10.1117/12.962746.

22. Vladimirov A. P., Eremin P. S. Relative displacement determination of surfaces of two objects by means of speckle-field dynamic interference in the image plane // Proc. SPIE. - 2003, Vol. 5067. - P. 91-98. - DOI: 10.1117/12.518490.

23. Vladimirov A. P., Kapustin D. S. Comparative analysis of dynamic and holographic interferometry methods with reference to deformations of a membrane // Russian Journal of Nondestructive Testing. -2004 . - Vol. 40, iss. 1. - P. 61-65.

24. Методы акустического контроля металлов / Под ред. Н. П. Алешина. - М.: Машиностроение, 1989. - 456 с.

25. Базылев П. В., Бондаренко А. Н., Луговой В. А. Лазерная установка для измерения скорости распространения поверхностных волн Рэлея // Дефектоскопия. - 1990. - № 10. C. 91-93.

26. Measurement of the complex amplitude of transient surface acoustic waves using double-pulsed TV holography and a two-stage spatial Fourier transform method / C. Trillo, A. F. Doval, D. Cernadas, O. Lopez, J. C. Lopez, B. V. Dorrı, J. L. Fernandez, M. Perez-Amor // Measurement Science and Technology. - 2003. - Vol. 14, no. 12. - P. 2127-2134. DOI: $10.1088 / 0957-0233 / 14 / 12 / 012$.

27. Microdistortions in the crystal lattice of steel IIIX15 as estimated via the optoacoustic method and velocimetry / A. P. Vladimirov, E. S. Gorkunov, P. S. Eremin, S. M. Zadvorkin // Russian Journal of Nondestructive Testing. - 2006. - Vol. 42, iss. 9. - P. 582-585. DOI: $10.1134 / \mathrm{S} 1061830906090038$.

28. A speckle-interferometric setup for contactless measurements of the velocity of Rayleigh ultrasonic waves / A. P. Vladimirov, E. S. Gorkunov, P. S. Eremin, S. M. Zadvorkin, M. V. Shadrin, K. E. Solov'ev // Instruments and Experimental Techniques. - 2010. - Vol. 53, iss. 1. - P. 118-121. - DOI: 10.1134/S0020441210010197.

29. A speckle-interferometric setup for determining the velocity of ultrasonic rayleigh waves on millimeter-size segments / A. P. Vladimirov, E .S. Gorkunov, L. S. Goruleva, S. M. Zadvorkin, M. V. Shadrin // Russian Journal of Nondestructive Testing. - 2011. - Vol. 47, iss. 3. - P. 153-157. - DOI: $10.1134 / \mathrm{S} 1061830911030107$.

30. Magnetic nondestructive evaluation of fatigue damage of ferromagnetic steels for nuclear fusion energy systems / A. Gilanyi, K. Morishita, T. Sukegawa, M. Uesaka, K. Miya // Fusion Engineering and Design. - 1998. - Vol. 42, iss. 1-4. - P. 485-491.

31. Тупикин Д. А. Термоэлектрический метод контроля усталостных явлений // Контроль. Диагностика. - 2003. - № 11. - С. 53-61.

32. Игнатович С. Р., Шмаров В. Н., Юцкевич С. С. Особенности формирования деформационного рельефа на поверхности сплава Д16АТ при усталости // Авиационнокосмическая техника и технология. - 2009. - Т. 67. - № 10. - С. 132-135.

Vladimirov A. P. / Dynamic speckle interferometry of microscopic and macroscopic processes in deformable media 
33. Ермишкин В. А., Мурат Д. П., Подбельский В. В. Применение фотометрического анализа структурных изображений для оценки сопротивления усталостному разрушению // Автоматизация и современные технологии. - 2008. - № 2. - С. 11-21.

34. Плехов О. А., Пантелеев И. А., Леонтьев В. А. Особенности выделения тепла и генерации сигналов акустической эмиссии при циклическом деформировании армко-железа // Физическая мезомеханика. - 2009. - Т. 12, № 5. - С. 37-43.

35. Маром Е. Голографическая корреляция // Голографические неразрушающие исследования. - М.: Машиностроение, 1979. - С. 164-194.

36. Marom E., Muller R. K. Optical correlation for impending fatigue failure detection // International Journal of Nondestructive Testing. - 1971. - Vol. 3, iss. 2. - P. 171-187.

37. Kozubenlo V. P., Potichenko V. A., Borodin Yu. S. Examination of fatigue of metals by the speckle-correlation // Strength of Materials. - 1989. - Vol. 21, iss. 7. - P. 953-958. DOI: $10.1007 / \mathrm{BF} 01529623$.

38. Kamantsev I. S., Vladimirov A. P., Borodin Е. М. Исследование процессов зарождения трещин при многоцикловой усталости трубной стали 09Г2С с использованием метода спеклинтерферометрии // Vestnik TGU. - 2013. - Vol. 18. iss. 4. - P. 1881-1882.

39. Изучение процесса зарождения усталостной трещины по изменению рельефа поверхности образца и ее спекловых изображений / A. P. Vladimirov, I. S. Kamantsev, A. V. Ishchenko, E. S. Gorkunov, S. V. Gladkovsky // Deformatsiya i razrushenie materialov. 2015. - No. 1. - P. 21-26.

40. Using speckle images correlation for real-time inspection of fatigue crack initiation and propagation / A. P. Vladimirov, I. S. Kamantsev, V. E. Veselova, S. V. Gladkovski // Proc. SPIE. 2015. - Vol. 9525. - P. 952525: 1-6. - DOI: 10.1117/12.2184703.

41. Dynamic Laser Speckle and Applications / Edited by H. J. Rabal and R. A. Braga. - CRC Press, 2008.

42. Briers J. D. Laser speckle contrast imaging for measuring blood flow // Optica Applicata. 2007. - Vol. 37, issue 1-2. - P 139-152.

43. A speckle-interferometric device for studying the cell biological activity / A. S. Malygin, N. V. Bebenina, A. P. Vladimirov, K. N. Mikitas, A. A. Baharev // Instruments and Experimental Techniques. - 2012. - Vol. 55, iss. 3. - P. 415-418.

44. Retrofit Device for Real-Time Evaluation of Metabolic Activity in Herpes Virus Infected Cell Cultures / A. P. Vladimirov, A. S. Malygin, Yu. A. Mikhailova, A. A. Bakharev, A. P. Poryvaeva // Biomedical Engineering. - 2014. - Vol. 48, iss. 14. - P. 178-181. DOI: $10.1007 / \mathrm{s} 10527-014-9447-9$.

45. Application of speckle dynamics for studies of cell metabolism / A. P. Vladimirov, A. A. Baharev, A. S. Malygin, J. A. Mikhailova, I.A. Novoselova, D. I. Yakin // Proc. SPIE. 2015. Vol. 9529. P. 95291F: 1-10.

46. Dynamic speckle-interferometer for intracellular processes analyses at high optical magnification / A. A. Baharev, A. P. Vladimirov, A. S. Malygin, Y. A. Mikhailova, I. A. Novoselova, D. I. Yakin, A. V. Druzhinin // Proc. SPIE. - 2015. - Vol. 9529. P. 95291G: 1-9.

47. Тихомиров А.М. Импеданс биологических тканей и его применение в медицине. М : РГМУ, 2006. - 12 c. 